\title{
An assessment of recently released high-degree global geopotential models based on heterogeneous geodetic and ocean data
}

Yihao Wu ( $\nabla$ yihaowu@hhu.edu.cn )

Hohai University

\section{Adili Abulaitijiang}

Technical University of Denmark

\section{Xiufeng He}

Hohai University

\section{Zhicai Luo}

Huazhong University of Science and Technology

\section{Haihong Wang}

Wuhan University

\section{Boyang Zhou}

Guangdong University of Technology

\section{Full paper}

Keywords: Global geopotential model assessment, heterogeneous gravity data, ocean reanalysis data, mean dynamic topography, geostrophic current

Posted Date: October 1st, 2020

DOl: https://doi.org/10.21203/rs.3.rs-83076/v1

License: (9) This work is licensed under a Creative Commons Attribution 4.0 International License. Read Full License

Version of Record: A version of this preprint was published at Frontiers in Earth Science on September 14th, 2021. See the published version at https://doi.org/10.3389/feart.2021.749611. 


\section{Abstract}

The development of the state-of-the-art global geopotential model (GGM) broadens its applications in ocean science, which emphasizes the importance for model assessment. We validate the recently released high-degree GGMs over the South China Sea using geodetic observations and synthetic/ocean reanalysis data. The assessment against a recently conducted high resolution $(\sim 3 \mathrm{~km})$ airborne gravimetric survey over the Paracel Islands shows that XGM2019e_2159 has the highest accuracy ( 3.1 $\mathrm{mGal}$ ). However, the comparison with airborne/shipborne data hardly discriminate the qualities of other GGMs that have or truncated to same degree and order. Whereas, the validation results of GGMs against synthetic/ocean data are not identical. XGM2019e_2159/XGM2019 has the best quality, and the accuracy of associated mean dynamic topography (MDT) is $2.5 \mathrm{~cm}$, and this value changes to $7.1 \mathrm{~cm} / \mathrm{s}$ $(6.8 \mathrm{~cm} / \mathrm{s})$ when the zonal (meridian) geostrophic currents are assessed. In contrast, the assessments of other GGMs show that they have deteriorated accuracies compared to XGM2019e_2159/XGM2019; in particular, the widely used EGM2008 has the worst performance, and the accuracies of associated MDT and zonal (meridian) currents are reduced by $3.9 \mathrm{~cm}$ and $4.0 \mathrm{~cm} / \mathrm{s}(5.5 \mathrm{~cm} / \mathrm{s})$, respectively, compared to results derived from XGM2019e_2159/XGM2019. These results suggest that the choice of GGM in oceanographic research is crucial, especially in coastal zones and regions that only fill-in data were used for GGM development. Moreover, the existing synthetic/ocean data may be served as an additional data source for global/regional gravity field assessment, which is especially useful in regions that lack of control data.

\section{Introduction}

The knowledge of global geopotential model (GGM) enables a wealth of applications in ocean science. For instance, the combination of GGM and satellite altimetry data allows to monitoring ocean state from space in a global scale (Bingham et al. 2011a; Knudsen et al. 2011; Volkov and Zlotnicki 2012; Rio et al. 2014), which is beneficial for studying coastal ecosystem processes and understanding heat and energy cycles as well as water exchanges over oceanic areas. Moreover, GGM facilitates the applications in height datum unification (e.g., Rummel 2012; Wu et al. 2016; Filmer et al. 2018), the study of oceanic lithosphere (e.g., Kaban et al. 1999; Rummel et al. 2002; Tenzer et al. 2015), and oil/gas explorations as well as other offshore activities (e.g., Braitenberg and Ebbing 2009; Rio et al. 2011; Sampietro 2015).

The wide applications of GGMs emphasize the improvement of these models in terms of accuracy and spatial resolution. The state-of-the-art spaceborne techniques, such as Gravity Recovery and Climate Experiment (GRACE) (e.g., Tapley et al. 2003, 2005) and Gravity Field and Steady-State Ocean Circulation Explorer (GOCE) (e.g., Pail et al. 2011), improve GGM at long wavelength with unprecedented accuracy and spatial resolution (Pail et al. 2010; Bruinsma et al. 2013; Brockman et al. 2014). However, the low resolution of satellite-only GGM derived from GRACE/GOCE data remains a barrier for ocean state study at medium- and short-wavelength bands, especially for wavelength shorter than $~ 100 \mathrm{~km}$ (e.g., Jayne 2006; Albertella et al. 2012). Satellite-only model can be enhanced by combining satellite altimetry measurement as well as airborne and surface (terrestrial and shipborne) gravity data, and the enhanced 
solution is the so-called combined GGM. The combined GGM dramatically improve the accuracy and spatial resolution of global gravity field, and the widely used high-degree model like EGM2008/EIGEN-6C4 represents the global gravity field at a resolution of $\sim 10 \mathrm{~km}$ (Pavlis et al. 2012, 2013; Förste et al. 2014). Consequently, the use of combined GGM allows to map the mean ocean circulation at more detailed scales than satellite-only model (e.g., Andersen et al. 2009; Vianna and Menezes 2010).

However, large uncertainties were found in combined GGM attempting to study the detailed mean ocean state at a regional scale, by a magnitude of decimeter level, e.g., see Farrell et al. (2012). These uncertainties are attributed to two main aspects. First, the noise in observation propagated into GGM, known as commission errors. The properties of commission errors are heterogeneous considering GGMs were computed with different data and data preprocessing strategies. Second, GGM lacks the ability to recover the short-wavelength signals beyond its maximal expansion degree, known as omission errors. The uncertainty in GGM may cause strong oscillations up to the magnitude of decimeter level, particularly in regions that only fill-in data were used in GGM development, and this remains a major obstacle to oceanographic studies and geophysical investigations (McAdoo et al. 2013; Skourup et al. 2017; Fecher et al. 2017). Moreover, combined GGM that computed by merging altimetry-derived data suffer from the coastal problem (e.g., Huang et al. 2017; Wu et al. 2019), since the altimeter data contain larger errors close to coast/island than in open seas, due to the severely contaminated waveforms and deteriorated geophysical corrections (Deng and Featherstone 2006; Andersen and Scharroo 2011; Abulaitijiang et al. 2015).

Whereas, the development of satellite altimetry leads to the improvement of marine gravity field, and the solution computed with recent altimetry data (e.g., CryoSat-2, Jason, SARAL/Altika) shows improved accuracy compared to the one derived from old altimeter data (e.g. Geosat and ERS-1), by a factor of 2 to 4 (Sandwell et al. 2013, 2014; Garcia et al. 2014). As a result, the GGMs that developed with recent altimeter data may have better quality. In addition, the accumulation of high-quality satellite altimetry/gravimetry data and the improved data preprocessing strategies as well as weighting schemes may further contribute to improve combined GGM (e.g., Fecher et al. 2017). Given the fact that GGM plays a more important role in ocean science than ever, it is crucial for evaluating the recently released GGM before they are used for oceanographic researches; however, little attention has been paid to model assessments over oceans. This study focuses on the assessment of recently released high-degree GGMs over a local area, where no locally surveyed gravity data have been combined for GGM development. This study provides an insight into the qualities of GGMs at other oceanic areas that only fill-in or altimetryderived data were used for model development, e.g., most regions of Asia. For validation purpose, the traditionally used geodetic observations (e.g., heterogeneous gravity data) are incorporated (e.g., Arabelos et al. 2010; Hirt et al. 2011); besides, ocean reanalysis data are used, which were successfully applied to validate altimeter-derived mean dynamic topography (MDT) and height datum unification (Ophaug et al. 2015; Idžanović et al. 2017; Filmer et al. 2018).

\section{Study Area And Data}


The South China Sea (SCS) is selected as the study area, which extends from $0^{\circ} \mathrm{N}$ to $24^{\circ} \mathrm{N}$ latitude and $99^{\circ} \mathrm{E}$ to $121^{\circ} \mathrm{E}$ longitude. The SCS is a semi-enclosed marginal sea, and it connects with the East China Sea, the Pacific, and the Indian Ocean through the Taiwan Strait, the Luzon Strait, and the Strait of Malacca, respectively (e.g., Ho et al. 2000), see Fig. 1 and the background information displays the bathymetry derived from the General Bathymetric Chart of the Oceans (GEBCO) (Weatherall et al. 2015). The SCS is dominated by seasonal monsoons with active mesoscale eddies (Jia and Liu, 2004; Gan et al. 2006; Chen et al. 2011) and major water exchanges occurring at the Taiwan Strait, Luzon Strait, and Sunda Shelf (e.g., Hwang and Chen, 2000). The ocean state study over the SCS presents particular challenges due to the complex topography, monsoon winds, and high variability of local hydrological conditions (Wang et al. 2003; Chen et al. 2011; Xu et al. 2012). This offers a good opportunity to assess the performances of recently published GGMs. In the following, heterogeneous geodetic observations and synthetic/ocean reanalysis data are introduced for model assessment.

\subsection{Global geopotential models}

Several recently published high-degree GGMs, i.e., EGM2008, EIGEN-6C4, GECO, SGG-UGM-1, GOCO05c, XGM2016, XGM2019, and XGM2019e_2159 are selected, and the associated information is seen in Table 1. The reason for choosing the models above is that these models have relatively higher spatial resolutions and better accuracies compared to most of other GGMs, see the validation results against the globally distributed GPS/levelling data in http://icgem.gfz-potsdam.de/home. An investigation of error degree variances offers an insight into the error spectra of GGM, regarded as internal error estimates, and it supplies a rudimentary quality assessment (e.g., Pail et al. 2011). Figure 2 shows the degree-wise accumulated error degree variances in terms of geoid height, demonstrates the error up to the maximal degree of each model. EGM2008 with the degree and order (d/o) of 2190 has large cumulative error, and its error rises rapidly from degrees 30-220, and reaches $\sim 7.3 \mathrm{~cm}$ by the degree of 220 and then increases slowly to $8.2 \mathrm{~cm}$. Whereas, the accumulated errors of models that have similar expansion degree and order as EGM2008, i.e., GECO (d/o 2190), SGG-UGM-1 (d/o 2159), EIGEN-6C4 (d/o 2190), and XGM2019e_2159 (d/o 2190) are reduced to approximately 4.2, 2.7, 3.4, and $3.1 \mathrm{~cm}$, respectively, which is a reduction by up to $67 \%$ compared to EGM2008's error. The prominent error in EGM2008 at the frequency bands between degree 30-220 is mainly due to the lack of GOCE data, and the other four models discussed above that developed with GOCE data have better quality in this frequency band, where GOCE data paly a dominate role (e.g., Gruber et al. 2010). Moreover, the combination of updated surface gravity data (e.g., terrestrial and altimetry-derived data) may be the reason that EIGEN-6C4/XGM2019e_2159 has smaller error than EGM2008 at short-wavelength band. The comparison of GGMs that have lower truncated degrees, i.e., GOCO05C (d/o 720), XGM2016 (d/o 719), and XGM2019 (d/o 760), show that GOCO05C has the largest error, and its error increases dramatically after degree 170 and reaches $12.5 \mathrm{~cm}$ at degree of 720 . Whereas, the cumulative error of XGM2016/XGM2019 is $\sim 1.1 / 2.5 \mathrm{~cm}$, which is smaller than that of GOCO05C.

It is noteworthy that the correlation of error coefficients of GGM is ignored when (accumulated) error degree variances are computed, and the GGM's uncertainties at a specific geographic location cannot be 
estimated. While, a more rigorous way for internal error estimate is implemented through error propagation by using the full error variance-covariance matrix of spherical harmonic coefficients (e.g., Balmino 2009). However, considering the limited accessibility of full error variance-covariance matrix of high-degree GGM and the associated huge computation load, this method may be not feasible. Moreover, polar gap problem exists in GGMs developed with GOCE data, which especially affects the accuracies of zonal and near-zonal coefficients (Pail et al. 2011). In total, error degree variances only supply a global mean of internal error and cannot be regarded as the realistic error estimate.

Table 1 Description of global geopotenital models 


\begin{tabular}{|c|c|c|c|}
\hline Model & $\begin{array}{c}\text { Expansion } \\
\text { degree }\end{array}$ & $\begin{array}{c}\text { Data used } \\
\text { for model } \\
\text { development }\end{array}$ & Remarks \\
\hline EGM2008 & 2190 & $\begin{array}{c}\text { GRACE } \\
\text { data, } \\
\text { terrestrial, } \\
\text { altimetry- } \\
\text { derived, and } \\
\text { airborne } \\
\text { gravity data }\end{array}$ & $\begin{array}{l}\text { EGM2008 was computed without GOCE data. The } \\
\text { DNSC07 data, which is the predecessor of DNSC08GRA, } \\
\text { was used over the South China Sea (Pavlis et al. 2012, } \\
\text { 2013) }\end{array}$ \\
\hline
\end{tabular}

GECO

$2190 \quad$ GOCE-only

GECO was computed by combining GOCE-only TIM R5

TIM R5 (d/o model into EGM2008 (Gilardoni et al. 2015). GOCE-only

250) and TIM R5 was developed by using satellite-to-satellite

EGM2008 tracking (SST) data and GOCE satellite gravity

gradiometry (SGG) data over the entire period (Pail et

al. 2011)

\begin{tabular}{|c|c|c|c|}
\hline SGG-UGM-1 & 2159 & $\begin{array}{l}\text { GOCE SST } \\
\text { and SGG } \\
\text { data, and } \\
\text { EGM2008 }\end{array}$ & $\begin{array}{l}\text { SGG-UGM-1 was developed by merging GOCE SST and } \\
\text { SGG (d/o 220) into EGM2008 (Liang et al. 2018) }\end{array}$ \\
\hline EIGEN-6C4 & 2190 & $\begin{array}{c}\text { LAGEOS, } \\
\text { GRACE } \\
\text { RL03, GOCE } \\
\text { SGG data, } \\
\text { and } \\
\text { terrestrial } \\
\text { data. }\end{array}$ & $\begin{array}{l}\text { Terrestrial data were DTU12 geoid data at ocean and } \\
\text { EGM2008 geoid height grid for continents (Förste et al. } \\
\text { 2014) }\end{array}$ \\
\hline GOCO05c & 720 & $\begin{array}{l}\text { GOCO05S, } \\
\text { and surface } \\
\text { gravity } \\
\text { anomaly } \\
\text { data }\end{array}$ & $\begin{array}{l}\text { GOCO05S (d/o 280) was developed by combining } \\
\text { GRACE (ITGS-Grace2014s), GOCE, kinematic orbits, } \\
\text { and satellite laser ranging (SLR) data. DTU13GRA- } \\
\text { derived data were used in ocean (Fecher et al. 2016) }\end{array}$ \\
\hline XGM2016 & 719 & $\begin{array}{l}\text { GOCO05S, } \\
\text { and surface }\end{array}$ & $\begin{array}{l}\text { XGM2016 was computed by combining GOCO05S and a } \\
\text { global } 15^{\prime} \times 15^{\prime} \text { grid provided by National Geospatial- } \\
\text { Page } 6 / 39\end{array}$ \\
\hline
\end{tabular}


XGM2019/

XGM2019e_2159
$760 / 2190$

GOCO06S, and surface

gravity data
XGM2019 and XGM2019e_2159 were developed using the same data, but the former was truncated to d/o 760 .

(Zingerle et al. 2019)

\subsection{Heterogeneous gravity data \\ 2.2.1 Airborne gravity disturbances}

The First Geodetic Surveying Team of Ministry of Natural Resources of China conducted an airborne gravimetric survey in 2018, covered the Paracel Islands that located in the northwest SCS, see the enclosed area of the red rectangle in Fig. 1. This area ranges from $15.5^{\circ} \mathrm{N}$ to $18.2^{\circ} \mathrm{N}$ latitude and $111.0^{\circ} \mathrm{E}$ to $113.3^{\circ} \mathrm{E}$ longitude. The airborne survey was implemented with a GT-2A gravimeter, which contained 87 flights in total to complete 61594 line kilometres, and it covered $~ 270$ kilometres in east-west direction and $\sim 325$ kilometres in north-south direction, see Fig. 3 . The survey lines were north-south oriented and spaced at $1 \mathrm{~km}$, while the control lines were east-west oriented and spaced at $5 \mathrm{~km}$. The height of flight ranged from 739 to $847 \mathrm{~m}$ above the mean sea level.

The GT-2A gravimeter recorded the raw data at a frequency of $18.75 \mathrm{~Hz}$, and the gravity data was calculated by subtracting the GPS-derived aircraft accelerations from the inertial accelerations, which were then corrected for the Eötvös effect and compensated for the off-level corrections. The derived gravity disturbances were filtered by a low pass filter with the cut-off frequency of $0.01 \mathrm{~Hz}$ to reduce highfrequency noise, which were then resampled to $2 \mathrm{~Hz}$ corresponding to the epoch of GPS measurements. The spatial resolution of the derived data after the filtering is $\sim 3 \mathrm{~km}$. The gravity data were referenced to the China Geodetic Coordinate System 2000 (CGCS 2000), and the geodetic coordinates were referenced to the GRS80 reference ellipsoid. Seven repeat lines were conducted for quality control, and the overall standard deviation (SD) of the variations of repeat lines was $~ 1.44 \mathrm{mGal}$. Moreover, the crossover measurements on survey/control lines offer an overview of the data quality, and the SD of the differences at crossovers was $1.54 \mathrm{mGal}$, showing in good agreement with the statistics of repeat lines. This airborne survey includes 1,854,900 point-wise data, which haven't been used for global/regional gravity field model modelling

\subsubsection{Shipborne gravity anomalies}

Marine gravity anomalies are retrieved from the National Geophysical Data Center (NGDC) from the National Centers for environmental information (NOAA), where worldwide shipborne gravity data collected during marine cruises from 1939 to present are available. The original data suffers from instrument errors, navigational errors, and biases stemming from the inconsistency of height systems as well as other systematic errors (e.g., Denker and Roland, 2005; Wu et al. 2017a). DTU17GRA is introduced 
to ensure the quality of shipborne data. This model combined the 25 years of satellite altimetry data and included recent geodetic mission data from Jason-1, CryoSat-2, and SARAL/Altika. The comparison with independent data showed that DTU17GRA had improved precision compared with the previous versions of altimetry-derived gravity database developed at DTU space (Andersen and Knudsen, 2019). The erroneous data are firstly removed through a 3-sigma rule, i.e., data are identified as blunders if the difference between shipborne data and DTU17GRA-derived quantities are larger than three times of the SD of all the differences. Since NGDC-derived data originated from various epochs and systematic errors were likely to exist, we applied a crossover adjustment to reduce the systematic errors. The duplicate data were removed and we assumed a constant bias for each track. Note that not all the systematic errors can be estimated due to the lack of track information for some cruises. The SD of the differences at crossovers was estimated as $8.4 \mathrm{mGal}$, which is slightly smaller than the SD of the difference between DTU17GRA-derived data and shipborne data before crossover adjustment $(\sim 9.0 \mathrm{mGal})$.

\subsection{Existing MDTs and Ocean models}

The performances of GGMs are investigated for MDT and geostrophic current recovery, where an existing synthetic MDT and three ocean models are introduced for cross validation. The synthetic MDT is called CNES-CLS13MDT, and it covers the period of 1993-2012 at a resolution $\sim 0.25^{\circ}(30 \mathrm{~km})$. This model was estimated using the CNES-CLS11 MSS data and EGM-DIR R4 (a satellite-only GGM) as the raw solution, which was then enhanced by in situ data to recover unresolved small-scale signals (Rio et al. 2011). Three ocean models, i.e., the Simple Ocean Data Assimilation, version 3 (SODA3) (Carton et al. 2018), the ocean reanalysis product of the European Centre for Medium-Range Weather Forecasts, version 5 (ECMWF ORAS5) (Zuo et al. 2017), and the Ocean Circulation and Climate Advanced Modeling Project (OCCAM) (Fox and Haines, 2003), are ocean reanalysis products provided with the field of dynamic topography. SODA3 was developed by ocean reanalysis with enhancements to model resolution, observation, forcing data, and the addition of active sea ice. This model maps the ocean state from 1980 to 2017 , and it has a $0.25^{\circ}$ horizontal resolution and 50 vertical levels. ORAS5 is a recently released ocean reanalysis product from the ECMWF and was developed based on Ocean ReAnalysis Pilot 5 (Zuo et al. 2017) using the same ocean and sea ice model and data assimilation method. ORAS 5 has a horizontal resolution of $0.25^{\circ}$ and 75 vertical levels, and it supplies monthly data from 1979 to 2018. The OCCAM MDT ( $0.5^{\circ}$ horizontal resolution) maps the ocean state from $1993-2004$, and was developed by a hydrodynamic model forced with wind stresses from the ECMWF, hydrographic data, and surface temperature (Fox and Haines, 2003).

\section{Results And Discussion}

\subsection{Validation against airborne/shipborne gravity data}

The expansion degrees of EGM2008, EIGEN-6C4, GECO, SGG-UGM-1, and XGM2019e_2159 are higher than those of XGM2016, XGM2019, and G0C005c. For the sake of comparison, the computations with the former five GGMs are not only carried out up to the maximal degrees but also truncate to degree 720 . 
Table 2 shows the statistics of the difference between the airborne gravity data and GGM-synthesized quantities at the flight altitude. The statistics derived from XGM2016, G0C005c, and GGMs that truncated to degree 720 are very close, the accuracies of which are all $~ 9.0 \mathrm{mGal}$. The GGMs truncate to $\mathrm{d} / \mathrm{o} 720$ cannot recover the spectral contents with the wavelengths shorter than $\sim 30.4 \mathrm{~km}$, and consequently, large inconsistencies are observed. Figure 4 demonstrates the discrepancy between GGM and airborne data (several representative models are displayed), and most significant misfits concentrate at regions close to islands that belong to the Paracel Islands (see Fig. 1). The reason may be due to the degraded quality of altimetry data used in developing GGMs, while airborne gravimetry does not suffer from the problem of waveform contamination as in satellite altimetry near coast/island and provides more accurate observations.

The expansion of GGMs with the degrees of 2190/2150 to the maximal degrees recover more small-scale signals and significantly reduce the discrepancies against the airborne data, i.e., by the magnitudes of $\sim 5$ mGal, compared to ones derived from the models truncated to 720 , see Table 2 . However, GGM with d/o of 2190 samples the gravity field at a resolution of $\sim 10 \mathrm{~km}$, which is inferior to the mean resolution of airborne data $(\sim 3 \mathrm{~km})$, and the high-frequency signals have the wavelength shorter than $10 \mathrm{~km}$ are missing in GGMs. As a result, the difference between GGM and airborne data demonstrate as highfrequency features.

The mutual comparisons show that EGM2008, GECO, and SGG-UGM-1 have comparable precisions, i.e., $4.0 \mathrm{mGal}$. GECO/SGG-UGM-1 that computed based on EGM2008 but with GOCE data does not demonstrate better result than EGM2008. Possible reason is that GOCE data mainly contribute to longwavelength bands (degree 30-220), and the effects introduced by GOCE data are not prominent in terms of gravity disturbances since they are dominated by local short-wavelength features. EIGEN-6C4 does not show improved accuracy compared to EGM2008/GECO/SGG-UGM-1, although EIGEN-6C4 was computed based on the updated altimetry data, i.e., DTU10GRA data, which have improved accuracy compared to the altimetry data used in developing EGM2008 (Andersen et al. 2010). Whereas, XGM2019e_2159 has the best quality and its accuracy is $\sim 3.2 \mathrm{mGal}$, and the discrepancy between XGM2019e_2159 and airborne data reduces dramatically close to islands, see Fig. 4. XGM2019e_2159 combined the recently released DTU13GRA data, which included the altimeter data from 1993-2013 with CryoSat-2 and Jason1 data (Andersen et al. 2013), and the comparison with independent marine/airborne surveys showed that DTU13GRA had superior quality than previous versions, e.g., DNSC08GRA and DTU10GRA data (Andersen et al. 2013). Thus, the incorporation of recent high quality altimetry data may be the main reason that XGM2019e_2159 has better accuracy than GGMs that have similar expansion degrees.

Table 2. Statistics of the difference between the airborne gravity data and quantities computed from GGMs over Paracel Islands. (units: mGal) 


\begin{tabular}{cccccc}
\hline & Degree & Max & Min & Mean & SD \\
\hline EGM2008 & 720 & 53.2 & -26.5 & -0.9 & 9.0 \\
EGM2008 & 2190 & 36.1 & -18.2 & -0.8 & 4.1 \\
EIGEN-6C4 & 720 & 54.4 & -25.2 & -0.6 & 9.1 \\
EIGEN-6C4 & 2190 & 35.4 & -16.5 & -0.4 & 3.9 \\
GECO & 720 & 54.0 & -25.9 & -0.7 & 9.0 \\
GECO & 2190 & 37.0 & -17.2 & -0.6 & 4.0 \\
SGG-UGM-1 & 720 & 53.6 & -25.1 & -0.8 & 9.0 \\
SGG-UGM-1 & 2159 & 36.6 & -17.0 & -0.7 & 4.0 \\
XGM2019e_2159 & 720 & 53.5 & -25.3 & -0.7 & 9.0 \\
XGM2019e2159 & 2190 & 29.9 & -16.4 & -0.6 & 3.1 \\
GOCO05C & 720 & 53.4 & -26.0 & -0.8 & 9.1 \\
XGM2016 & 719 & 53.4 & -26.3 & -0.7 & 9.0 \\
XGM2019 & 760 & 53.7 & -25.5 & -0.7 & 9.0 \\
XGM2019 & 720 & 53.7 & -25.4 & -0.7 & 8.98 \\
\hline
\end{tabular}

The SD of the differences between the shipborne gravity data and quantities synthesized from GGMs with the degrees of 2190/2159 are $9.4 \mathrm{mGal}$, see Table 3. However, the qualities of GGMs cannot be discriminated (see Fig. 5), and this is probably due to the limited accuracy of shipborne data, the quality of which may be questionable since some of them were collected decades ago without GPS navigation. Considering the restricted distribution of the airborne survey and suspicious quality of the shipborne data as well as the data voids of marine surveys in the western and northern SCS, the validation against local airborne/shipborne data cannot be treated as the representative error estimate of GGM over the South China Sea.

Table 3. Statistics of the difference between the shipborne gravity measurements and data synthesized from GGMs over South China Sea

\begin{tabular}{cccccc}
\hline & Degree & Max & Min & Mean & SD \\
\hline EGM2008 & 720 & 44.3 & -42.0 & 1.1 & 13.3 \\
EGM2008 & 2190 & 32.3 & -28.9 & 1.6 & 9.4 \\
EIGEN-6C4 & 720 & 44.7 & -42.7 & 1.0 & 13.5 \\
EIGEN-6C4 & 2190 & 32.6 & -29.5 & 1.5 & 9.5 \\
GECO & 720 & 44.5 & -42.4 & 1.1 & 13.4 \\
GECO & 2190 & 32.5 & -29.3 & 1.6 & 9.5 \\
SGG-UGM-1 & 720 & 44.4 & -42.1 & 1.1 & 13.3 \\
SGG-UGM-1 & 2159 & 32.3 & -28.9 & 1.6 & 9.4 \\
XGM2019e_2159 & 720 & 44.2 & -41.9 & 1.1 & 13.3 \\
XGM2019e-2159 & 2190 & 32.2 & -28.9 & 1.6 & 9.4 \\
GOCO05C & 720 & 44.4 & -42.1 & 1.2 & 13.3 \\
XGM2016 & 719 & 44.2 & -41.9 & 1.1 & 13.3 \\
XGM2019 & 760 & 44.2 & -41.9 & 1.1 & 13.3 \\
XGM2019 & 720 & 44.2 & -41.9 & 1.1 & 13.3 \\
\hline
\end{tabular}

\subsection{Mean dynamic topography comparison}

Before computing the geodetic MDT, we study the error information of different versions of MSS to choose an appropriate MSS. The interpolation errors of two recently released models, i.e., DTU15MSS (Andersen et al. 2015) and DTU18MSS (Andersen et al. 2018), are studied. Figure 6 shows the errors of MSS models, and the root mean square (RMS) of errors of DTU15MSS, and DTU18MSS are 1.95 and $1.78 \mathrm{~cm}$, respectively, which indicates that DTU18MSS has better quality. We observe DTU18MSS has better quality along the southern coast of Guangdong in China, the eastern coast of Vietnam and Malaysia, and the western coast of Luzon and coastal areas along Paiawan in Philippines. The reason 
that DTU18MSS outperforms DTU15MSS is mainly due to the incorporation more high-quality altimeter data and improved data pre-processing methods (Andersen et al. 2018).

MDT determined through a geodetic approach illustrates the departure of mean sea surface from geoid/quasi-geoid (e.g., Bingham et al. 2011a, 2014; Griesel et al. 2012). The raw geodetic MDT is computed as the difference between DTU18MSS and quasi-geoid computed from GGM truncated to its maximal degree. For cross validation, CNES-CLS13MDT, SODA3 MDT, ORAS5 MDT, and OCCAM MDT are introduced, where the former three models have a resolution of $0.25^{\circ}$, while the resolution of OCCAM is $0.5^{\circ}$. The raw geodetic MDT contains small-scale contents that cannot be resolved in synthetic/ocean data, and we apply a Gaussian filter with a correlation length of $60 \mathrm{~km}$ to the raw geodetic MDT for a spectrally consistent comparison with synthetic/ocean data. Different MDTs are referenced to various time periods, and we use the method suggested by Bingham and Haines (2006) to unify the time period, where all the models are adjusted to the geodetic MDT time period (1993-2018). The AVISO altimetric sea level anomaly (SLA) is used to standardize all the MDTs to the required period (e.g., Rio et al. 2011). The CNES-CLS13MDT is adjusted to the 1993-2018 period computed as CNES-CLS13MDT (93-2018) = CNES-CLS13MDT (93-2012) + MSLA (93-2018) - MSLA (93-2012), and MSLA denotes the mean value of SLA over a specific time period. For OCCAM MDT, a similar method is used to adjust the period to 1993-2018. For SODA3, we firstly compute the mean SODA MDT by averaging the monthly data from 1993 to 2017, which is then adjusted to 1993-2018 using the SLA data. For ORAS5, the associated MDT is retrieved by averaging the monthly data from 1993 to 2018 .

Different MDTs generally have analogous structures, vary in a range of around $0.5 \mathrm{~m}$, see Fig. 7 , where the maximum value (up to $0.9 \mathrm{~m}$ ) appears around the western coast of Cambodia; while, the minimum value (roughly $0.5 \mathrm{~m}$ ) occurs in the northern SCS. However, prominent discrepancy between GGM-derived MDT and synthetic/ocean model is observed, particularly in northern SCS, by a magnitude up to $10 \mathrm{~cm}$, where GGM-derived MDTs have smaller dynamic topography. The behaviors of MDTs computed from GGMs are heterogeneous, where the signals derived from EGM2008, GECO, SGG-UGM-1, and EIGEN-6C4 have more significant oscillations over the southern part, compared to ones calculated from other four GGMs. Moreover, the magnitude of MDT signals in synthetic/ocean model is not consistent, where CNESCLS13MDT has smaller values over northern SCS, while ORAS5 has larger signals around Luzon Strait.

Extreme values existing in GGM-derived MDT along the coast of Hainan, eastern coast of Vietnam, and western coast Brunei and Malaysia, are identified as outliers, due to the uncorrected errors in MSS and in quasi-geoid (e.g., Hipkin et al. 2004; Wu et al. 2017b, 2019). The remaining errors in MSS are mainly due to the orbit errors and errors in various range corrections (e.g., Andersen et al. 2009). However, these errors have been significantly reduced with the incorporation of recent altimeter data, even in coastal area, see Fig. 6. While, coastal quasi-geoid suffers from the scarcity of gravimetric data (e.g., shipborne/airborne data), degraded quality of altimetry-derived data, and bias/tilt among different data sets (e.g., Huang et al. 2017; Wu et al. 2019). The EGM2008 commission errors, composed of the low-degree errors estimated using a satellite-only model through error propagation and high-degree ones computed through a surface integral formula using surface gravity data (Pavlis et al. 2012), are seen in Appendix A. These errors reach 
decimetre level along the coastal regions, suggesting that the computed geodetic MDT prominently suffer from the errors in GGM, even though the application of filtering suppresses the high-frequency noises.

CNES-CLS13MDT and three ocean models are used as control data for model assessment, however, the lack of formal error of synthetic/ocean model remains an obstacle for deriving reliable results through an individual model. Thus, we not only provide the results computed from each synthetic/ocean model, but also give the statistics derived from the comparison with mean value of all synthetic/ocean models, which provide sufficient independence and redundancy to allow more robust comparison. Figure 8 demonstrates the discrepancy between MDT computed from GGM and mean of all synthetic/ocean data, where EGM2008-derived MDT has the largest oscillations, and the maximum/minimum value is $17.9 /-19.7 \mathrm{~cm}$, with a SD of $6.4 \mathrm{~cm}$, see Table 4. The significant long-wavelength errors are observed in EGM2008-derived MDT, by a magnitude of $\mathrm{cm}$ level, and this is probably due to the lack of GOCE data, and these long-wavelength errors are reduced when GGM with GOCE data is applied, i.e., see the result of GECO-/XGM2019e_2159-derived MDT in Fig. 8. Moreover, coastal problem is extremely prominent in the MDT computed from EGM2008, especially around the coast of Hainan, Vietnam, Malaysia, and Brunei, where errors reach more than $10 \mathrm{~cm}$. This is attributed to the use of lower quality of altimetry-derived data in EGM2008, and data voids occurred close to coast/island for the time when EGM2008 was computed, thus the quality of associated quasi-geoid become dubious. Moreover, since no locally surveyed gravity data (i.e., shipborne/airborne data) were involved in GGM computation, and altimetry data played a dominated role in gravity field recovery over SCS. In contrast, SGG-UGM-1-/GECO-derived MDT shows less variations and improved consistency against the ocean data, and the SD value reduces to $3.0 / 3.9 \mathrm{~cm}$. The incorporation of GOCE is the main reason that these two MDTs show improved performance at longwavelength band. Moreover, the application of GECO/SGG-UGM-1 substantially reduces the coastal errors, e.g., along the coast of Hainan and Vietnam. The mutual comparison shows GECO has better quality than SGG-UGM-1 in MDT modelling, where the different methods for model development and data merging/assimilation may account for these differences, though GECO and SGG-UGM-1 are both developed by combining EGM2008 and GOCE data. EIGEN-6C4 has comparable accuracy as GECO in MDT modelling, i.e., $3.1 \mathrm{~cm}$, and costal errors in EIGEN-6C4-derived MDT are reduced compared to the one derived from GECO/SGG-UGM-1. EIGEN-6C4 was also computed by combining GRACE, GOCE, and EGM2008 data, but it included DTU12 geoid data in ocean and this may be the main reason that EIGEN6 C4 has better performance than EGM2008/GECO/SGG-UGM-1 in coastal MDT computation. We also notice that more small-scale contents propagate into EIGEN-6C4-derived MDT, particularly in the southern SCS, indicating that the Gaussian filter may not be an optimal way to make a spectrally consistent fusion of MSS and GGM. The comparisons with local shipborne/airborne data show that these GGMs discussed above have identical qualities; moreover, these models typically show comparable accuracies when validated against GPS/levelling data, e.g., see Featherstone et al. (2018) and Wu et al. (2018). However, this is not true when comparing with synthetic/ocean data, where the accuracies of different models are heterogeneous.

The use of XGM2019e_2159 leads to a more consistent MDT with synthetic/ocean data, demonstrates less variations compared to the MDTs described above. The error of MDT calculated from 
XGM2019e_2159 is $2.5 \mathrm{~cm}$, with a reduction of $\sim 0.5 / 0.6 / 1.5 / 3.0 \mathrm{~cm}$, compared to MDT computed from GECO/EIGEN-6C4/SGG-UGM-1/EGM2008. The improved performance for XGM2019e_2159 is attributed to the combination of recent satellite gravimetry and altimetry data, where XGM2019e_2159 combined GOCO06s (a recently released GRACE/GOCE satellite-only model) at long wavelength and DTU13GRA data at short-wavelength. DTU13GRA has better quality than the previous versions, such as DTU10GRA, and the coastal gravity field in XGM2019e_2159 was improved accordingly. This result is commensurate with the validation against airborne data, where XGM2019e_2159 has the best quality.

For the MDTs computed with GGMs that have lower expansion degree and order, G0C005c-derived MDT has an accuracy of $2.9 \mathrm{~cm}$, while, the accuracy of XGM2016-/XGM2019-derived MDT is slightly better, by a magnitude of $0.3 / 0.4 \mathrm{~cm}$. XGM2016 was developed using the same methodology as for G0C005c, but the input surface data were heterogeneous, where G0C005c used DTU13GRA data, while XGM2016 combined NGA gridded data at ocean. XGM2019- and XGM2019e_2159-derived MDT have almost identical features, since XGM2019 was computed using the same input data and modelling method as XGM2019e_2159, but truncated to d/o 760.

The comparison of each synthetic/ocean model and GGM-derived MDT show that CNESCLS13MDT/SODA has smaller discrepancy against the geodetic MDTs, compared to ORAS5/OCCAM. This indicates that geodetic MDT may also be used for synthetic/ocean model assessment, particularly in regions lack of in situ data (e.g., buoys and hydrological profiles). However, it should be emphasized that these results are rudimentary ones since the error information of ocean model is not available and no in situ data over SCS can be used for evaluating synthetic/ocean model and geodetic MDT.

Table 4. The standard deviation of the difference between GGM-derived MDT and synthetic/ocean model

\begin{tabular}{cccccc}
\hline $\begin{array}{c}\text { Geodetic MDT minus } \\
\text { synthetic/ocean model }\end{array}$ & CNES-CLS13MDT & SODA & ORAS5 & OCCAM & $\begin{array}{c}\text { Mean of all } \\
\text { synthetic/ocean models }\end{array}$ \\
\hline EGM2008 & 6.0 & 6.4 & 7.3 & 6.8 & 6.4 \\
GECO & 2.9 & 3.0 & 3.7 & 4.4 & 3.3 \\
SGG-UGM-1 & 3.7 & 3.7 & 4.5 & 5.1 & 4.1 \\
EIGEN-6C4 & 3.0 & 3.0 & 3.8 & 4.4 & 3.3 \\
XGM2019e 2159 & 2.4 & 2.4 & 3.0 & 3.7 & 2.5 \\
GOCO05C & 2.5 & 2.7 & 3.4 & 3.9 & 2.9 \\
XGM2016 & 2.4 & 2.4 & 3.2 & 3.8 & 2.6 \\
XGM2019 & 2.3 & 2.4 & 3.1 & 3.7 & 2.5 \\
\hline
\end{tabular}

In addition, the geodetic MDT's behaviour along zonal/meridian profile is investigated. Figure 9 (a) shows the zonal mean of the misfit between geodetic MDT and the mean of all synthetic/ocean data. EGM2008derived MDT demonstrates strong oscillations and spike-like errors appear along this profile, by the magnitude up to $5 \mathrm{~cm}$. MDT derived from SGG-UGM-1/EIGEN-6C4 has slightly better performances, however, substantial spike errors are still prominent; for instance, MDT computed from SGG-UGM-1 has strong variations from $18^{\circ} \mathrm{N}$ to $21^{\circ} \mathrm{N}$, where this profile comes cross region around Hainan. This corresponds to the result that MDT derived from SGG-UGM-1 has large errors around Hainan because of coastal problem. By contrast, MDTs computed from other GGMs show improved quality, and almost no apparent spikes are found. XGM2019-/XGM2019e_2159-derived MDT has the smallest variation, and the discrepancy against the synthetic/ocean data is within $3 \mathrm{~cm}$. The errors in MDTs are reduced along the 
meridian profile compared to the ones along the zonal profile, see Fig. 9 (b), and this is due to the configuration of satellite orbits, which affects the error structure of GGM-derived geoid heights. As orbit of GRACE/GOCE is almost south-north oriented, the along-track data sampling is much denser than that in the across-track direction; and consequently, larger errors were found in east-west direction than in northsouth direction (e.g., Balmino 2009; Bingham et al. 2011b). Similar validation results are concluded along the meridian profile as ones derived from the zonal profile, where the signals calculated from XGM2019/XGM2019e_2159 has the best quality.

\subsection{Geostrophic ocean currents comparison}

The performances of GGMs are further validated in terms of geostrophic currents. Apart from the synthetic/ocean data shown in Sect. 2.3, another reanalysis dataset derived from an ocean data assimilation system in Asia, the Indian Ocean, and the western Pacific Ocean (AIPO), known as AIPOcean (Yan et al. 2015), is introduced. AIPOcean data was developed based on the ensemble optimal interpolation (EnOI) method, where various types of observations including SLA from AVISO, sea surface temperature and salinity profiles, Global Temperature-Salinity Profile Program, and Array for Real-time Geostrophic Oceanography and Arctic Synoptic Basin-wide Oceanography, were assimilated. AIPOcean data contains daily-averaged three dimensional temperature, salinity, ocean currents from January 1 , 1993 to December 31, 2006, with a horizontal resolution of $0.25^{\circ}$ and 22 vertical levels. The comparison of AIPOcean data with independent observations and other reanalysis products shows that the quality of AIPOcean data was well controlled, which generally provide the realistic structures of ocean variability in AlPO (Yan et al. 2015).

AIPOcean data map ocean currents from 1993 to 2006 with a horizontal resolution of $0.25^{\circ}$, and synthetic/geodetic MDT is adjusted to this time period based on AVISO altimetric SLA data, and then the geostrophic velocities are computed. Whereas, surface currents provided in ocean model are retrieved and averaged to map the signals over the 1993-2006 time period. Figure 10 shows the zonal velocities computed from GGMs and synthetic/ocean data, which generally reconstruct the surface circulation of SCS. For instance, the blue strip-like features over the northern of SCS that passes through the southern of Hainan is the South China Sea Warm Current (SCSWC), playing a key role in distribution of mass, energy, and heat balances over the northern SCS (Hsueh and Zhong 2004; Chiang et al. 2008; Yang et al. 2008). Moreover, the yellow/red signals along Guangdong coast are known as Guangdong Coastal Current (GCC) (Hu et al. 2000; Gu et al. 2012), however, the structures of GCC are not identical in different models. For instance, the intensity of GCC in CNES-CLS13MDT/SODA is not as strong as in ORAS5/OCCAM/AIPO.

The detailed features of zonal velocities derived from GGMs and ocean data are heterogeneous. For signals computed from GGMs, more scattered structures are observed in EGM2008-derived currents, displaying as prominent long-wavelength patterns, especially in southern SCS. However, these large-scale contents cannot be treated as real ocean-circulation signals, since the long-wavelength content of EGM2008 is questionable due to the lack of GOCE data. In contrast, the velocities computed from other 
GGMs show less variations and smoother patterns. It is noticeable that GGM notoriously suffers from the coastal problem, where the errors in MDT are magnified in ocean current computation, since the geostrophic velocities are computed as the gradients of MDT. However, the coastal problem can be mitigated by using the recent altimeter data (e.g., Ophaug et al. 2015; Idžanović et al. 2017) and airborne gravimetric survey (e.g., Hwang et al. 2006; Wu et al. 2019).

CNES-CLS13MDT and SODA demonstrate smoother structures than other ocean models over the southern SCS, and significant small-scale structures are observed in CNES-CLS13MDT over the northern part. While, ORAS5, OCCAM, and AIPO have more intense features over the Guangdong coast, compared to CNES-CLS13MDT/SODA. Different methods and input data for model development are the main reasons for these differences. For example, CNES-CLS13MDT is a synthetic model, estimated through a geodetic method as a raw solution, and then enhanced by in situ data to recover unresolved small-scale contents. While, ocean models are the ocean reanalysis products developed by combining ocean state data, hydrographic data, surface temperature, and so on.

Figure 11 demonstrates the discrepancy between the zonal geostrophic currents computed from GGMs and the mean of all synthetic/ocean data, and the associated statistics are given in Table 5. The performances of GGMs are heterogeneous, and EGM2008-derived zonal velocities have largest oscillations, where the SD of the inconsistency against the mean of synthetic/ocean data is $11.1 \mathrm{~cm} / \mathrm{s}$. The prominent discrepancy occurs over the southern of SCS and along coast of Vietnam, Malaysia and Paiawan, by a magnitude up to $20 \mathrm{~cm} / \mathrm{s}$. These inconsistencies demonstrate as significant longwavelength features, which are attributed to the lack of GOCE data in EGM2008. The comparison of EGM2008 and other models that have similar resolutions (i.e., GECO, SGG-UGM-1, EIGEN-6C4, and XGM2019e_2159) shows that these models have improved quality, and the errors are reduced to 7.1 $7.9 \mathrm{~cm} / \mathrm{s}$. The combination of GOCE data and updated altimetry-derived data are the main reasons that these models have superior quality. The coastal errors of ocean currents computed from these four models are significantly reduced, especially in southern coast of Guangdong, north-eastern and southeastern coast of Vietnam, western coast of Malaysia and Paiawan. The mutual comparison shows that GECO-/XGM2019e_2159-derived zonal velocities have better qualities than ones computed from SGGUGM-1/EIGEN-6C4, where the accuracy of zonal currents computed from GECO/XGM2019e_2159 is $7.1 \mathrm{~cm} / \mathrm{s}$, while the accuracy of signals derived from SGG-UGM-1/EIGEN-6C4 is reduced to $7.7 / 7.9 \mathrm{~cm} / \mathrm{s}$. This is not consistent with the results derived from MDT comparison, where GECO-derived MDT has lower quality than MDT computed from XGM2019e_2159, but with comparable quality as EIGEN-6C4-derived signals. The accuracies of zonal velocities computed from GOC005c, XGM2016, and XGM2019 are 7.4, 7.4 , and $7.1 \mathrm{~cm} / \mathrm{s}$, respectively, where XGM2019-derived signals shows better performance. This is identical with the results derived from MDT comparison, where XGM2019 and XGM2019e_2159 demonstrate identical performances in MDT computation.

The comparison of individual synthetic/ocean model with GGM-derived velocities show that CNESCLS13MDT/SODA has smaller discrepancy against geostrophic currents computed from GGM, and the SD of the difference between CNES-CLS13MDT/SODA-derived velocities and the mean of signals 
computed from all GGMs is $7.2 / 7.0 \mathrm{~cm} / \mathrm{s}$. Whereas, this value increases to $7.8 \mathrm{~cm} / \mathrm{s}$ when AIPO is compared. ORAS5/OCCAM displays largest misfits, and the SD value increases to $8.5 / 8.4 \mathrm{~cm} / \mathrm{s}$. However, the scarcity of in situ data and lack of accuracy information make it difficult to derive a realistic error estimate of ocean model.

Table 5 The standard deviation of the difference between the zonal velocities synthesized from GGMs and those derived from synthetic/ocean data

\begin{tabular}{ccccccc}
\hline $\begin{array}{c}\text { MDT minus synthetic/ocean } \\
\text { model }\end{array}$ & $\begin{array}{c}\text { CNES- } \\
\text { CLS13MDT }\end{array}$ & SODA & ORAS5 & OCCAM & AIPO & $\begin{array}{c}\text { Mean of all } \\
\text { synthetic/ocean } \\
\text { models }\end{array}$ \\
\hline EGM2008 & 11.4 & 11.2 & 13.2 & 12.6 & 11.8 & 11.1 \\
GECO & 7.6 & 7.5 & 8.9 & 8.5 & 8.3 & 7.1 \\
SGG-UGM-1 & 8.0 & 8.0 & 9.6 & 9.1 & 8.9 & 7.7 \\
EIGEN-6C4 & 8.0 & 8.2 & 9.5 & 9.0 & 9.0 & 7.9 \\
XGM2019e2159 & 7.7 & 7.4 & 9.0 & 8.2 & 8.3 & 7.4 \\
GOCO05C & 8.1 & 7.7 & 9.2 & 8.6 & 8.5 & 7.4 \\
XGM2016 & 7.8 & 7.7 & 9.1 & 8.5 & 8.5 & 7.1 \\
XGM2019 & 7.7 & 7.4 & 9.0 & 8.3 & 8.3 & \\
\hline
\end{tabular}

The meridian velocities synthesized from GGMs and synthetic/ocean data are seen in Fig. 12, representing the north-southward ocean circulation of SCS. For instance, a southward along-shelf current is seen along the coast of Vietnam, see the blue stripe-like features, which is mainly caused by local monsoon system (e.g., Hu et al. 2000; Chen et al. 2012). In addition, the red signals cross the Luzon Strait are line with the Kuroshio intrusion, e.g., see Hu et al. (2000) and Xue et al. (2004). The validation results are seen in Fig. 13 and Table 6, where EGM2008 still has the worst performances, the error of the associated velocities reaches $12.3 \mathrm{~cm} / \mathrm{s}$. Whereas, the corresponding errors are reduced to 7.6, 8.0, 8.6, and $6.8 \mathrm{~cm} / \mathrm{s}$, respectively, when the velocities derived from GECO, SGG-UGM-1, EIGEN-6C4, and XGM2019e_2159 are assessed. These results are not identical as ones derived from the zonal velocities. The accuracy of meridian currents derived from G0C005c, XGM2016, and XGM2019 is 7.7, 7.3, and $6.9 \mathrm{~cm} / \mathrm{s}$, respectively, where XGM2019-derived velocities also have better performance.

Table 6 The standard deviation of the difference between the meridian velocities synthesized from GGMs and those derived from synthetic/ocean models

\begin{tabular}{ccccccc}
\hline $\begin{array}{c}\text { MDT minus synthetic/ocean } \\
\text { model }\end{array}$ & $\begin{array}{c}\text { CNES- } \\
\text { CLS13MDT }\end{array}$ & SODA & ORAS5 & OCCAM & AIPO & $\begin{array}{c}\text { Mean of all } \\
\text { synthetic/ocean } \\
\text { models }\end{array}$ \\
\hline EGM2008 & 13.2 & 12.5 & 13.6 & 13.8 & 12.7 & 12.3 \\
EIGEN-6C4 & 9.7 & 9.0 & 10.4 & 10.0 & 9.1 & 8.6 \\
GECO & 8.6 & 7.8 & 9.6 & 9.4 & 8.4 & 7.6 \\
SGG-UGM-1 & 9.2 & 8.1 & 9.6 & 9.7 & 8.7 & 8.0 \\
XGM2019e 2159 & 7.9 & 7.2 & 9.0 & 8.3 & 8.0 & 6.8 \\
GOCO05C & 8.8 & 8.1 & 9.8 & 8.9 & 8.4 & 7.7 \\
XGM2016 & 8.1 & 7.7 & 9.4 & 8.6 & 8.3 & 7.3 \\
XGM2019 & 7.8 & 7.2 & 9.0 & 8.3 & 8.0 & 6.9 \\
\hline
\end{tabular}

\section{Conclusions}

Wide range of applications of GGMs in ocean science emphasizes the importance for model assessment. We assess the performances of recently released high-degree GGMs over the South China Sea, where local geodetic data (i.e., airborne/shipborne gravity data) and synthetic/ocean reanalysis data are served as the control data. 
A comparison with a recently conducted high resolution $(\sim 3 \mathrm{~km})$ airborne gravimetric survey over the Paracel Islands shows that XGM2019e_2159 has the best quality, the accuracy of which is $\sim 3.1 \mathrm{mGal}$. While, the accuracies of EGM2008, GECO, SGG-UGM-1, and EIGEN-6C4 decrease to $4.0 \mathrm{mGal}$, however, the qualities of these models cannot be discriminated. The errors of GGMs that have or truncated to d/o 720 increase to $\sim 9.0 \mathrm{mGal}$, since the small-scale signals cannot be recovered by GGM that truncated to lower d/o. In contrast, the shipborne gravity data that retrieved from NGDC cannot discriminate the accuracies of GGMs that have same expansion degrees, due to the limited data precision.

The assessment against synthetic/ocean data show that the accuracies of GGMs are heterogeneous, though the signals computed from GGMs generally reconstruct the surface circulation features of SCS. XGM2019e_2159 has the best quality, showing in agreement with the validation results against airborne data. The SD of the difference between XGM2019-/XGM2019e_2159-derived MDT and the mean of all synthetic/ocean data is $\sim 2.5 \mathrm{~cm}$, and this value changes to $7.1 \mathrm{~cm} / \mathrm{s}(6.8 \mathrm{~cm} / \mathrm{s})$ when the zonal (meridian) currents are assessed. The assessments of EIGEN-6C4, GECO, SGG-UGM-1, G0CO05c, and XGM2016 show that they have deteriorated qualities than XGM2019e_2159/XGM2019, by magnitudes ranging from 0.1 to $1.6 \mathrm{~cm}$ in terms of MDT, and 0.4 to $1.8 \mathrm{~cm} / \mathrm{s}$ when geostrophic velocities are evaluated. EGM2008-derived signals demonstrate the largest oscillations, where the accuracy of associated MDT reduces to $6.4 \mathrm{~cm}$, and this value decreases to $11.1 \mathrm{~cm} / \mathrm{s}(12.3 \mathrm{~cm} / \mathrm{s})$ when the zonal (meridian) velocities are assessed. The lack of GOCE data is the main reason for prominent longwavelength errors presenting in oceanic signals calculated from EGM2008. Moreover, EGM2008-derived contents severely suffer from the coastal problem, which is mainly attributed to the lack of high-quality altimetry-derived data for the time this model was developed.

Numerical results suggest that the choice of GGM in ocean state study is crucial, particularly in regions that only fill-in data were used for model development, even though different GGMs may show comparable results when compared with geodetic data (e.g., airborne/shipborne data and GPS/levelling data). Moreover, synthetic/ocean data are capable of distinguishing GGMs at the frequency band that have the wavelengths longer that $\sim 30 \mathrm{~km}$, indicating that these data may be served as an additional data source for validating global/regional gravity field model at oceans.

\section{Abbreviations}

GGM: global geopotential model; MDT: mean dynamic topography; GRACE: Gravity Field and Climate Experiment; GOCE: Gravity Field and Steady-State Ocean Circulation Explorer; SCS: South China Sea; GEBCO: General Bathymetric Chart of the Oceans; EIGEN: European Improved Gravity Model of the Earth by New Techniques; d/o: degree and order; GPS: Global Positioning System; NGDC: National Geophysical Data Center; NOAA: National Centers for environmental information; SODA: Simple Ocean Data Assimilation; ECMWF: European Centre for Medium-Range Weather Forecasts; OCCAM: Ocean Circulation and Climate Advanced Modeling.

\section{Declarations}




\section{Acknowledgments}

The authors gratefully acknowledge the First Geodetic Surveying Brigade of the Ministry of Natural Resources of China for kindly providing the airborne gravity data.

\section{Authors' contributions}

$\mathrm{YW}$ initiated the study, designed the numerical experiments and wrote the manuscript. $A A, X H, Z L$, and HW provided the data and gave the beneficial suggestions. YW, AA, and BZ finalized the manuscript. All authors read and approved the final manuscript.

\section{Funding}

This study was supported by the National Natural Science Foundation of China (No. 42004008), the Natural Science Foundation of Jiangsu Province, China (No. BK20190498), the Fundamental Research Funds for the Central Universities (No. B200202019), and the Beijing Key Laboratory of Urban Spatial Information Engineering (No. 2020213).

\section{Availability of data and materials}

The EGM2008 model and the associated errors are available from https://doi.org/earthinfo.nga.mil/GandG/wgs84/gravitymod/egm2008/egm08_wgs84.html, while other global geopotential models are accessed from http://icgem.gfz-potsdam.de/home. DTU17GRA and DTU15MSS/DTU18MSS and the associated error grids are available on https://doi.org/ftp.space.dtu.dk/pub. Shipborne gravity data from National Geophysical Data Center are available from https://doi.org/www.ngdc.noaa.gov/. CNES-CLS13MDT and AVISO altimetric sea level anomalies can be publicly accessed from https://doi.org/www.aviso.altimetry.fr/en/data/products.html. SODA3 is available on http://dsrs.atmos.umd.edu/DATA/soda3.12.2/REGRIDED/ocean/, ORAS5 is accessed from http://icdc.cen.uni-

hamburg.de/thredds/catalog/ftpthredds/EASYInit/oras5/ORCA025/sossheig/opa4/catalog.html, and AIPOcean is available at ftp://data.argo.org.cn/pub/ARGO/aipocean1.0/.

\section{Competing interests}

The authors declare that they have no competing interests.

\section{References}


Abulaitijiang A, Andersen OB, Stenseng L (2015) Coastal sea level from inland CryoSat-2 interferometric SAR altimetry. Geophys Res Lett 42(6):1841-1847. https://doi.org/10.1002/2015GL063131

Albertella A, Savcenko R, Janjić T, Rummel R, Bosch W, Schröter J (2012) High resolution dynamic ocean topography in the Southern Ocean from GOCE. Geophys J Int 190(2):922-930. https://doi.org/10.1111/j. 1365-246X.2012.05531.x

Andersen OB (2010) The DTU10 global gravity field and mean sea surface - improvements in the Arctic, In: 2nd IGFS symposium, Fairbanks, Alaska

Andersen OB, Knudsen P (2009) DNSC08 mean sea surface and mean dynamic topography models. J Geophys Res 114:C11001. https://doi.org/10.1029/2008JC005179

Andersen OB, Knudsen P (2019) The DTU17 Global Marine Gravity Field: First Validation Results. In: International Association of Geodesy Symposia, Springer, Berlin, Heidelberg

Andersen OB, Knudsen P, Kenyon S, Factor J, Holmes SA (2013) The DTU13 Global marine gravity fieldfirst evaluation. In: Ocean Surface Topography Science Team Meeting, Boulder, Colorado.

Andersen OB, Knudsen P, Stenseng L (2018) A New DTU18 MSS Mean Sea Surface-Improvement from SAR Altimetry, In: 25 years of progress in radar altimetry symposium, Portugal

Andersen OB, Piccioni G, Knudsen P, Stenseng L (2015) The DTU15 Mean Sea Surface and Mean Dynamic Topography - focusing on Arctic issues and development. In: OSTST Meeting, Reston, USA

Andersen OB, Scharroo R (2011) Range and geophysical corrections in coastal regions: and implications for mean sea surface determination. In: Vignudelli et al (eds) Coastal altimetry, Springer, Berlin, Heidelberg

Arabelos DN, Tscherning CC (2010) A comparison of recent Earth gravitational models with emphasis on their contribution in refining the gravity and geoid at continental or regional scale. J Geod 84(11):643660. https://doi.org/10.1007/s00190-010-0397-z

Balmino G (2009) Efficient propagation of error covariance matrices of gravitational models: application to GRACE and GOCE. J Geod 83(10):989-995. https://doi.org/ 10.1007/s00190-009-0317-2

Bingham RJ, Haines K (2006) Mean dynamic topography: Intercomparisons and errors. Phil Trans R Soc: Series A 364(1841):903-916. https://doi.org/10.1098/rsta.2006.1745

Bingham RJ, Haines K, Lea DJ (2014) How well can we measure the ocean's mean dynamic topography from space?. J Geophys Res Oceans 119:3336-3356. https://doi.org/10.1002/2013JC009354

Bingham RJ, Knudsen P, Andersen O, Pail R (2011a) An initial estimate of the North Atlantic steady-state geostrophic circulation from GOCE. Geophys Res Lett 38:L01606.

https://doi.org/10.1029/2010GL045633 
Bingham RJ, Tscherning C, Knudsen P (2011b) An initial investigation of the GOCE error variance covariance matrices in the context of the GOCE user toolbox project. In: Proceedings of 4th International GOCE User Workshop European Space Agency, ESA

Braitenberg C, Ebbing J (2009) New insights into the basement structure of the West Siberian Basin from forward and inverse modeling of GRACE satellite gravity data. J Geophys Res Solid Earth 114:B06402. https://doi.org/10.1029/2008JB005799

Brockman, JM, Zehentner N, Höck E, Pail R, Loth I, Mayer-Gürr T, Schuh WD (2014) EGM_TIM_RL05: An independent geoid with centimeter accuracy purely based on the GOCE mission Geophys Res Lett 41:8089-8099, https://doi.org/10.1002/2014GL061904

Bruinsma SL, Förste C, Abrikosov O, Marty JC, Rio MH, Mulet S, Bonvalot S (2013) The new ESA satelliteonly gravity field model via the direct approach. Geophys Res Lett 40:3607-3612. https://doi.org/10.1002/grl.50716

Carton JA, Chepurin GA, Chen L (2018) SODA3: a new ocean climate reanalysis. J Climate 31:69676983. https://doi.org/10.1175/JCLI-D-18-0149.1

Chen C, Lai Z, Beardsley RC, Xu Q, Lin H, Viet NT (2012) Current separation and upwelling over the southeast shelf of Vietnam in the South China Sea. J Geophys Res Oceans 117:C03033. https://doi.org/10.1029/2011JC007150

Chen G, Hou Y, Chu X (2011) Mesoscale eddies in the South China Sea: Mean properties, spatiotemporal variability, and impact on thermohaline structure. J Geophys Res Oceans 116:C06018. https://doi.org/10.1029/2010JC006716

Cheng L, Zhang Z, Zhao W, Tian J (2015) Temporal variability of the current in the northeastern South China Sea revealed by 2.5-year-long moored observations. J Oceanogr 71(4):361-372. https://doi.org/10.1007/s10872-015-0295-3

Chiang TL, Wu CR, Chao SY (2008) Physical and geographical origins of the South China Sea warm current. J Geophys Res Oceans 113:C08028. https://doi.org/10.1029/2008JC004794

Deng X, Featherstone WE (2006) A coastal retracking system for satellite radar altimeter waveforms: Application to ERS2 around Australia. J Geophys Res Oceans 111:(C06012). https://doi.org/ 10.1029/2005JC003039

Denker H, Roland M (2005) Compilation and evaluation of a consistent marine gravity data set surrounding Europe. In: A Window on the Future of Geodesy, Springer, Berlin, Heidelberg

Fang W, Fang G, Shi P, Huang Q, Xie Q (2002) Seasonal structures of upper layer circulation in the southern South China Sea from in situ observations, J Geophys Res Oceans 107(C11):3202. https://doi.org/10.1029/2002JC001343 
Featherstone WE, McCubbine JC, Brown NJ, Claessens SJ, Filmer MS, Kirby JF (2018) The first Australian gravimetric quasigeoid model with location-specific uncertainty estimates. J Geod, 92(2):149-168. https://doi.org/ 10.1007/s00190-017-1053-7

Fecher T, Pail R, Gruber T (2017) G0C005c: A new combined gravity field model based on full normal equations and regionally varying weighting. Surv Geophys 38(3):571-590. https://doi.org/ 10.1007/s10712-016-9406-y

Filmer MS, Hughes CW, Woodworth PL, Featherstone WE, Bingham RJ (2018) Comparisons between geodetic and oceanographic approaches to estimate mean dynamic topography for vertical datum unification: evaluation at Australia tide gauge. J Geod 92(12):1413-1437. https://doi.org/0.1007/s00190-018-1131-5

Fox AD, Haines K (2003) Interpretation of water transformations diagnosed from data assimilation. J Phys Oceanogr 33:485-498. https://doi.org/10.1175/1520-0485(2003)033<0485:IOWMTD>2.0.C0;2

Förste C, Bruinsma SL, Abrikosov O, Lemoine JM, Schaller T, Götze HJ, Ebbing J, Marty JC, Flechtner F, Balmino R, Biancale R (2014) EIGEN-6C4 The latest combined global gravity field model including GOCE data up to degree and order 2190 of GFZ Potsdam and GRGS Toulouse, The 5th GOCE User Workshop, Paris, France

Gan J, Li H, Curchitser EN, Haidvogel DB (2006) Modeling South China Sea circulation: Response to seasonal forcing regimes. J Geophys Res Oceans 111:C06034. https://doi.org/10.1029/2005JC003298

Garcia ES, Sandwell DT, Smith WHF (2014) Retracking CryoSat-2, Envisat and Jason-1 radar altimetry waveforms for improved gravity field recovery. Geophys J Int 196(3):1402-1422.

https://doi.org/10.1093/gji/ggt469

Gilardoni M, Reguzzoni M, Sampietro D (2015) GECO: a global gravity model by locally combining GOCE data and EGM2008. Stud Geophys Geod 60(2):228-247. doi.org/10.1007/s11200-015-1114-14

Griesel A, Mazloff MR, Gille ST (2012) Mean dynamic topography in the Southern Ocean: Evaluating Antarctic Circumpolar Current transport. J Geophys Res Oceans 117:C01020.

https://doi.org/10.1029/2011JC007573

Gruber T, Rummel R, Abrikosov O, van Hees R (2014) GOCE Level 2 Product Data Handbook, GO-MA-HPFGS-0110, Issue 4.2, available at: https://doi.org/earth.esa.int/documents/ 10174/1650485/GOCE_Product_Data_Handbook_Level-2

Gu Y, Pan J, Lin H (2012) Remote sensing observation and numerical modeling of an upwelling jet in Guangdong coastal water. J Geophys Res Oceans 117:C08019. https://doi.org/10.1029/2012JC007922

Hipkin RG, Haines K, Beggan C, Bingley R, Hernandez F, Holt J, Baker T (2004) The geoid EDIN2000 and mean sea surface topography around the British Isles. Geophys J Int 157(2):565-577. 
Hirt C, Gruber T, Featherstone WE (2011) Evaluation of the first GOCE static gravity field models using terrestrial gravity, vertical deflections and EGM2008 quasigeoid heights. J Geod 85(10):723-740. https://doi.org/10.1007/s00190-011-0482-y

Ho CR, Zheng Q, Soong YS, Kuo NJ, Hu JH (2000) Seasonal variability of sea surface height in the South China Sea observed with TOPEX/Poseidon altimeter data. J Geophys Res Oceans, 105(C6):1398113990. https://doi.org/10.1029/2000JC900001

Hsueh Y, Zhong L (2004) A pressure-driven South China Sea Warm Current. J Geophys Res Oceans 109:C09014. https://doi.org/10.1029/2004JC002374

Hu J, Kawamura H, Hong H, Qi Y (2000) A review on the currents in the South China Sea: seasonal circulation, South China Sea warm current and Kuroshio intrusion. J Oceanogr 56(6):607-624. https://doi.org/ 10.1023/A:1011117531252

Huang J (2017) Determining coastal mean dynamic topography by geodetic methods. Geophys Res Lett, 44:11,125-11,128. https://doi.org/10.1002/2017GL076020

Hwang C, Chen SA (2000) Circulations and eddies over the South China Sea derived from TOPEX/Poseidon altimetry. J. Geophys Res Oceans 105(C10):23943-23965.

https://doi.org/10.1029/2000JC900092

Hwang C, Guo J, Deng X, Hsu HY, Liu Y (2006) Coastal gravity anomalies from retracked Geosat/GM altimetry: improvement, limitation and the role of airborne gravity data. J Geod 80(4):204-216. https://doi.org/ 10.1007/s00190-006-0052-x

Idžanović M, Ophaug V, Andersen OB (2017) The coastal mean dynamic topography in Norway observed by CryoSat-2 and GOCE. Geophys Res Lett 44(11):5609-5617. https://doi.org/10.1002/2017GL073777

Jayne SR (2006) Circulation of the North Atlantic Ocean from altimetry and the Gravity Recovery and Climate Experiment geoid. J Geophys Res 111:C03005. https://doi.org/10.1029/2005JC003128

Jia Y, Liu Q (2004) Eddy shedding from the Kuroshio bend at Luzon Strait. J Oceanogr 60:1063-1069, https://doi.org/1010.1007/s10872-10005-10014-10876

Kaban, MK, Schwintzer P, Tikhotsky SA (1999) A global isostatic gravity model of the Earth. Geophys J Int 136(3):519-536. https://doi.org/10.1046/j.1365-246x.1999.00731.x

Knudsen P, Bingham R, Andersen OB, Rio MH (2011) A global mean dynamic topography and ocean circulation estimation using a preliminary GOCE gravity model. J Geod 85(11):861-879. doi 10.1007/s00190-011-0485-8 
Liang W, Xu X, Li J, Zhu G (2018) The determination of an ultra-high gravity field model SGG-UGM-1 by combining EGM2008 gravity anomaly and GOCE observation data. Acta Geodaetica et Cartographica Sinica 47(4):425-434. https://doi.org/10.11947/j.AGCS.2018.20170269

McAdoo DC, Farrell SL, Laxon S, Ridout A, Zwally HJ, Yi D (2013) Gravity of the Arctic Ocean from satellite data with validations using airborne gravimetry: Oceanographic implications. J Geophys Res Oceans 118: 917-930. https://doi.org/10.1002/ jgrc.20080

Ophaug V, Breili K, Gerlach C (2015) A comparative assessment of coastal mean dynamic topography in Norway by geodetic and ocean approaches. J Geophys Res Oceans 120(12):7807-7826. https://doi.org/10.1002/2015JC011145.

Pail R, Fecher T, Barnes D, Factor JF, Holmes SA, Gruber T, Zingerle P (2018) Short note: the experimental geopotential model XGM2016. J Geod 92(4):443-451. https://doi.org/10.1007/s00190-017-1070-6.

Pail R, Goiginger H, Schuh W-D, Höck E, Brockmann JM, Fecher T, Gruber T, Mayer-Gürr T, Kusche J, Jäggi A, Rieser D (2010) Combined satellite gravity field model GOCO01S derived from GOCE and GRACE. Geophys Res Lett 37:L20314. https://doi.org/10.1029/2010GL044906

Pail R, et al. (2011) First GOCE gravity field models derived by three different approaches. J Geod 85(11):819-843. https://doi.org/10.1007/s00190-011-0467-x

Pavlis NK, Holmes SA, Kenyon SC, Factor JK (2012) The development and evaluation of Earth Gravitational Model (EGM2008). J Geophys Res Solid Earth 117:B04406.

https://doi.org/10.1029/2011JB008916

Pavlis NK, Holmes SA, Kenyon SC, Factor JK (2013) Correction to "The development and evaluation of the Earth Gravitational Model 2008 (EGM2008)". J Geophys Res Solid Earth 118(5):2633. https://doi.org/ 10.1029/jgrb.50167

Rio MH, Guinehut S, Larnicol G (2011) New CNES-CLS09 global mean dynamic topography computed from the combination of GRACE data, altimetry, and in situ measurements. J Geophys Res Oceans 116:C07018. https://doi.org/10.1029/2010JC006505

Rio MH, Mulet S, Picot N (2014) Beyond GOCE for the ocean circulation estimate: Synergetic use of altimetry, gravimetry, and in situ data provides new insight into geostrophic and Ekman currents. Geophys Res Lett 41(24):8918-8925. https://doi.org/10.1002/2014GL061773

Rummel R (2012) Height unification using GOCE. Journal of geodetic science 2(4):355-362. https://doi.org/ 10.2478/v10156-011-0047-2

Rummel R, Balmino G, Johannessen J, Visser P, Woodworth P (2002) Dedicated gravity field missionsprinciples and aims. J Geodyn 33(1-2):3-20. https://doi.org/10.1016/S0264-3707(01)00050-3 
Sampietro D (2015) Geological units and Moho depth determination in the Western Balkans exploiting GOCE data. Geophys J Int 202(2):1054-1063. https://doi.org/10.1093/gji/ggv212

Sandwell DT, Garcia E, Soofi K, Wessel P, Smith WHF (2013) Towards $1 \mathrm{mGal}$ global marine gravity from CryoSat-2, Envisat, and Jason-1. The Leading Edge 32(8):892-899.

https://doi.org/10.1190/tle32080892.1

Sandwell, D.T., Müller, R.D., Smith, W.H.F., Garcia, E., and Francis, R. (2014), New global marine gravity model from CryoSat-2 and Jason-1 reveals buried tectonic structure, Science, 346(6205):65-67, $10.1126 /$ science. 1258213

Skourup H, Farrell SL, Hendricks S, Ricker R, Armitage TWK, Ridout A, Andersen OB, Haas C, Baker S (2017) An assessment of state-of-the-art mean sea surface and geoid models of the Arctic Ocean: Implications for sea ice freeboard retrieval. J Geophys Res Oceans 122:8593-8613. doi.org/10.1002/2017JC013176

Tapley B, Chambers D, Bettadpur S, Ries J (2003) Large scale ocean circulation from the GRACE GGM01 geoid. Geophys Res Lett 30(22):2163. https://doi.org/10.1029/2003GL018622

Tapley B, Ries J, Bettadpur S, Chambers D, Cheng M, Condi F, Gunter B, Kang Z, Nagel P, Pastor R, Pekker T, Poole S, Wang F (2005) GGM02 - An improved Earth gravity field model from GRACE. J Geod 79:467478. https://doi.org/10.1007/s00190-005-0480-z

Tenzer R, Chen W, Tsoulis D, Bagherbandi M, Sjöberg LE, Novák P, Jin S (2015) Analysis of the refined CRUST1.0 crustal model and its gravity field. Surv Geophys 36(1):139-165.

https://doi.org/10.1007/s10712-014-9299-6

Wang G, Su J, Chu PC (2003) Mesoscale eddies in the South China Sea observed with altimeter data. Geophys Res Lett 30:2121. https://doi.org/10.1029/2003GL018532

Weatherall P, Marks KM, Jakobsson M, Schmitt T, Tani S, Arndt JE, Rovere M, Chayes D, Ferrini V, Wigley R (2015) A new digital bathymetric model of the world's oceans, Earth Space Sci 2:331-345. https://doi.org/10.1002/2015EA000107

Wu Y, Abulaitijiang A, Featherstone WE, McCubbine JC, Andersen OB (2019) Coastal gravity field refinement by combining airborne and ground-based data. J Geod 93(12):2569-2584. https://doi.org/ $10.1007 /$ s00190-019-01320-3

Wu Y, Luo Z, Chen W, Chen Y (2017a) High-resolution regional gravity field recovery from Poisson wavelets using heterogeneous observational techniques. Earth Planets Space 69(34):1-15. https://doi.org/10.1186/s40623-017-0618-2

Wu Y, Luo Z, Mei X, Lu J (2016) Normal Height Connection across Seas by the Geopotential-Difference Method: Case Study in Qiongzhou Strait, China. J Surv Eng 143(2):05016011. 
Wu Y, Luo Z, Zhong B, Xu C (2018) A multilayer approach and its application to model a local gravimetric quasi-geoid model over the North Sea: QGNSea V1.0. Geosci Model Dev 11:4797-4815. https://doi.org/ 10.5194/gmd-11-4797-2018

Wu Y, Zhou H, Zhong B, Luo Z (2017b) Regional gravity field recovery using the GOCE gravity gradient tensor and heterogeneous gravimetry and altimetry data. J Geophys Res Solid Earth 122(8):6928-6952. https://doi.org/ 10.1002/2017JB014196

Xu D, Zhu J, Qi Y, Li X, Yan Y (2012) The impact of mean dynamic topography on a sea-level anomaly assimilation in the South China Sea based on an eddy-resolving model. Acta Oceanol Sin 31(5):11-25. https://doi.org/ 10.1007/s13131-012-0232-x

Xue H, Chai F, Pettigrew N, Xu D, Shi M, Xu J (2004) Kuroshio intrusion and the circulation in the South China Sea. J Geophys Res Oceans 109:C02017. https://doi.org/10.1029/2002JC001724

Yan C, Zhu J, Xie J (2015) An ocean data assimilation system in the Indian Ocean and West Pacific Ocean. Adv Atmos Sci 32(11):1460-147. https://doi.org/10.1007/s00376-015-4121-z

Yang J, Wu D, Lin X (2008) On the dynamics of the South China Sea warm current. J Geophys Res Oceans 113:C08003. https://doi.org/10.1029/2007JC004427

Yu Z, Shen S, McCreary JP, Yaremchuk M, Furue R (2007) South China Sea throughflow as evidenced by satellite images and numerical experiments. Geophys Res Lett 34:L01601.

https://doi.org/10.1029/2006GL028103

Zingerle, P, Pail, R, Gruber, T, Oikonomidou, X (2019) The experimental gravity field model XGM2019e. GFZ Data Services. https://doi.org/10.5880/ICGEM.2019.007

Zuo H, Balmaseda MA, Mogensen K (2017) The new eddy-permitting ORAP5 ocean reanalysis: description, evaluation and uncertainties in climate signals. Clim Dyn 49:791. https://doi.org/10.1007/s00382-015-2675-1

Vianna ML, Menezes VV (2010) Mean mesoscale global ocean currents from geodetic pre-GOCE MDTs with a synthesis of the North Pacific circulation. J Geophys Res Oceans 115:C02016. https://doi.org/10.1029/2009JC005494

Volkov DL, Zlotnicki V (2012) Performance of GOCE and GRACE-derived mean dynamic topographies in resolving Antarctic Circum-polar Current fronts, Ocean Dyn 62(6):893-905. https://doi.org/10.1007/s10236-012-0541-9

\section{Figures}




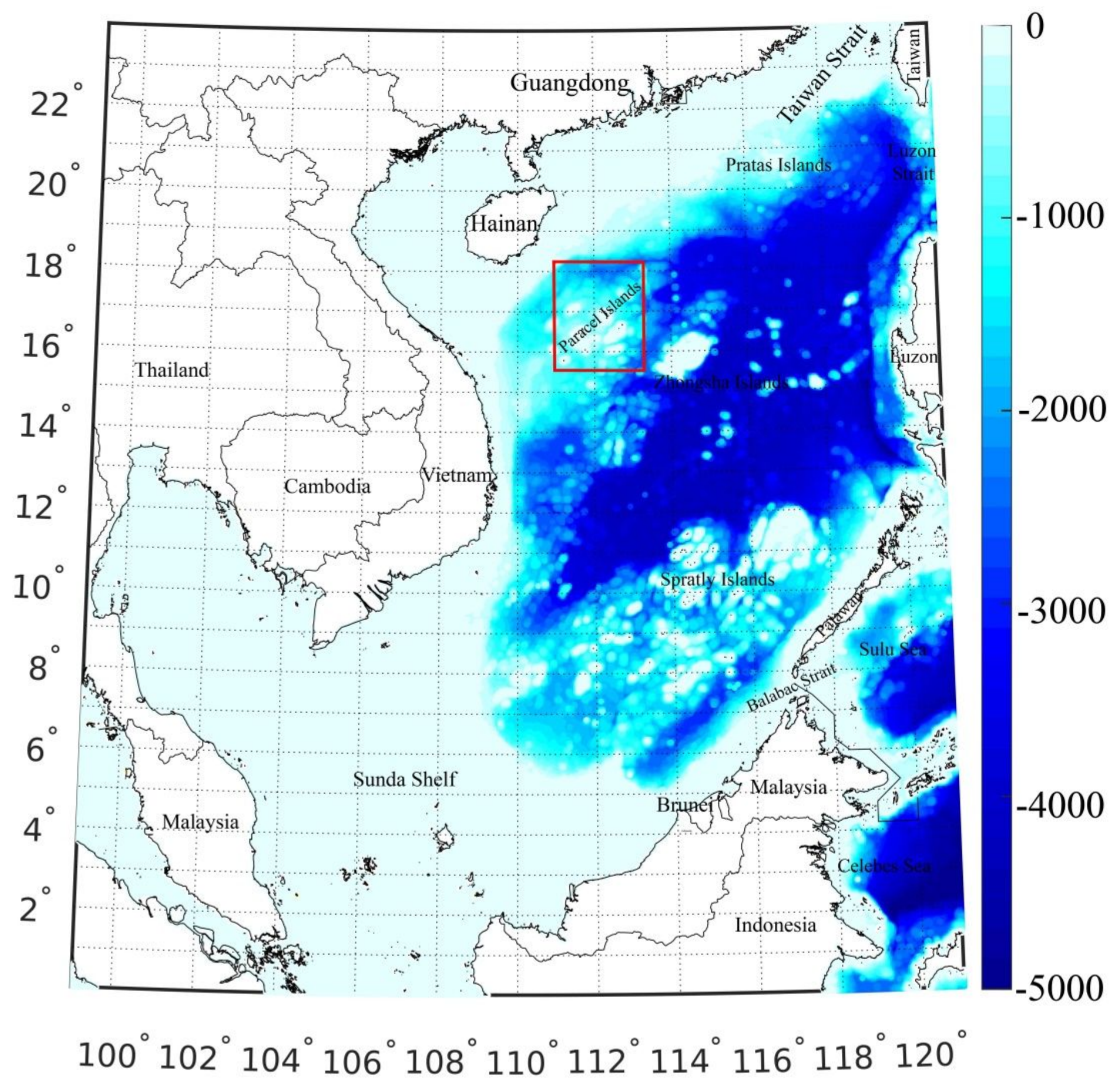

Figure 1

The study area and the associated bathymetry. The region enclosed in the red rectangle represents the surveyed area of an airborne gravimetry over the Paracel Islands. Note: The designations employed and the presentation of the material on this map do not imply the expression of any opinion whatsoever on the part of Research Square concerning the legal status of any country, territory, city or area or of its authorities, or concerning the delimitation of its frontiers or boundaries. This map has been provided by the authors. 


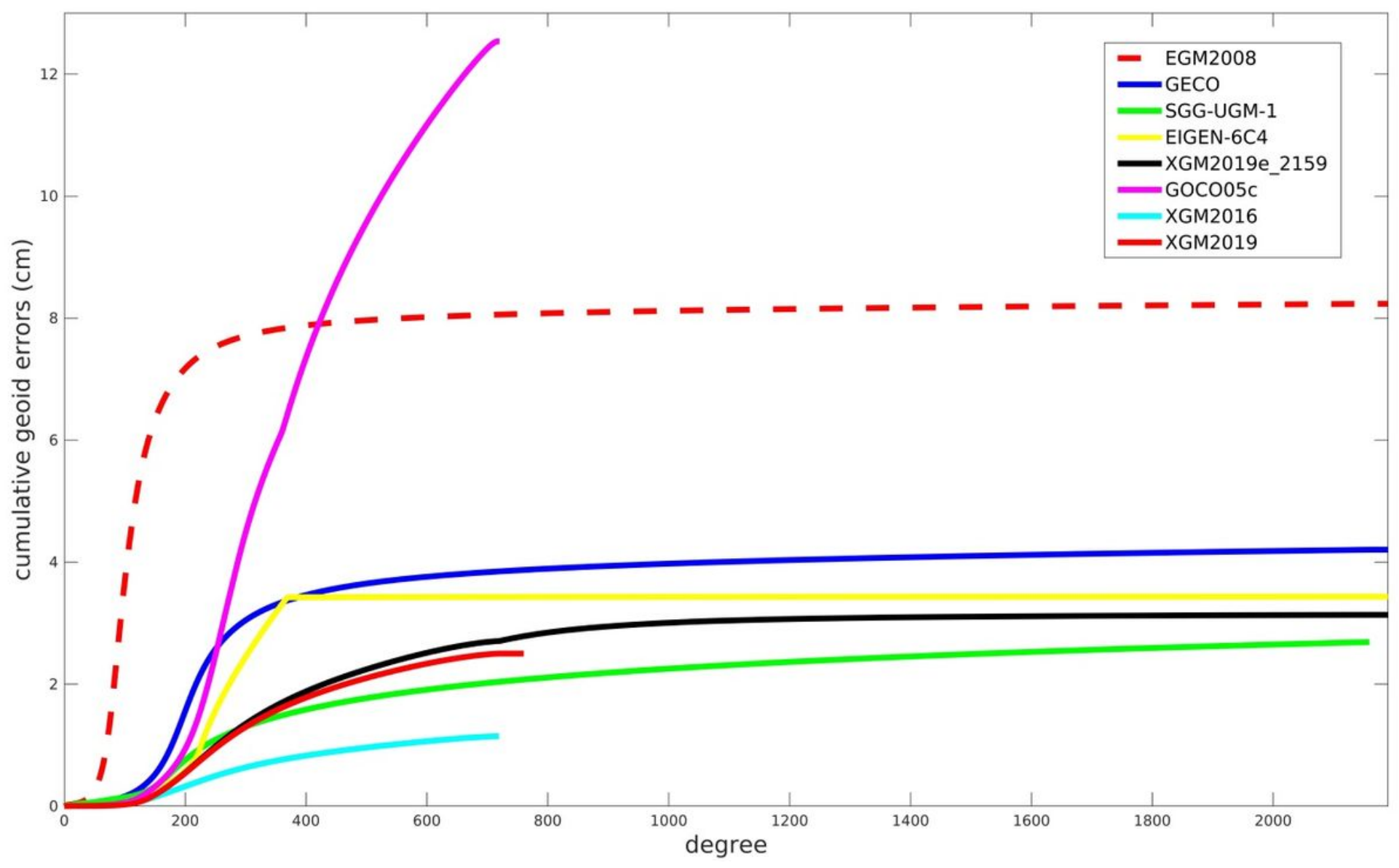

Figure 2

Cumulative geoid errors of GGMs as a function of spherical expansion degree 


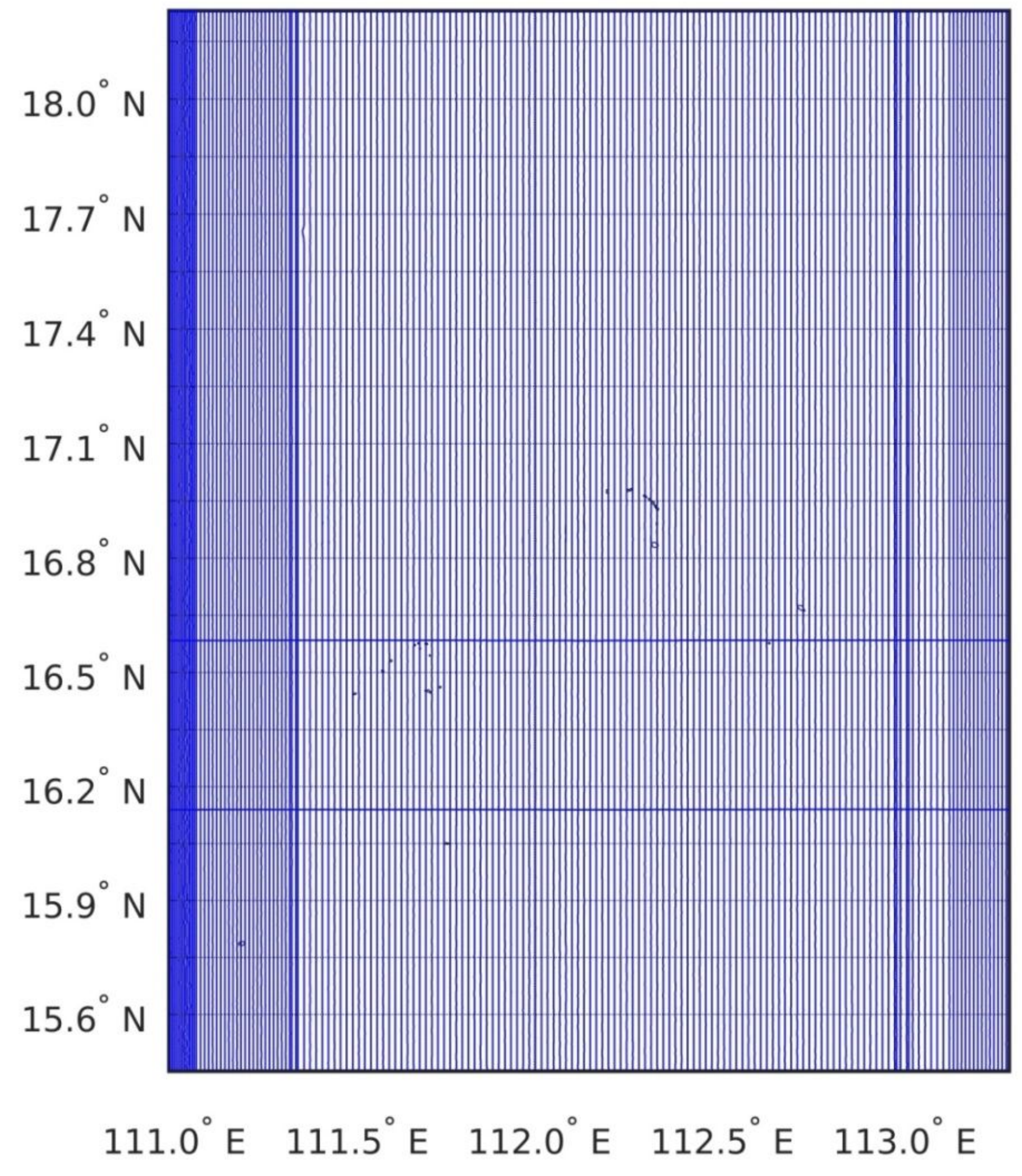

Figure 3

Flight lines of airborne gravimetric survey over the Paracel Islands 

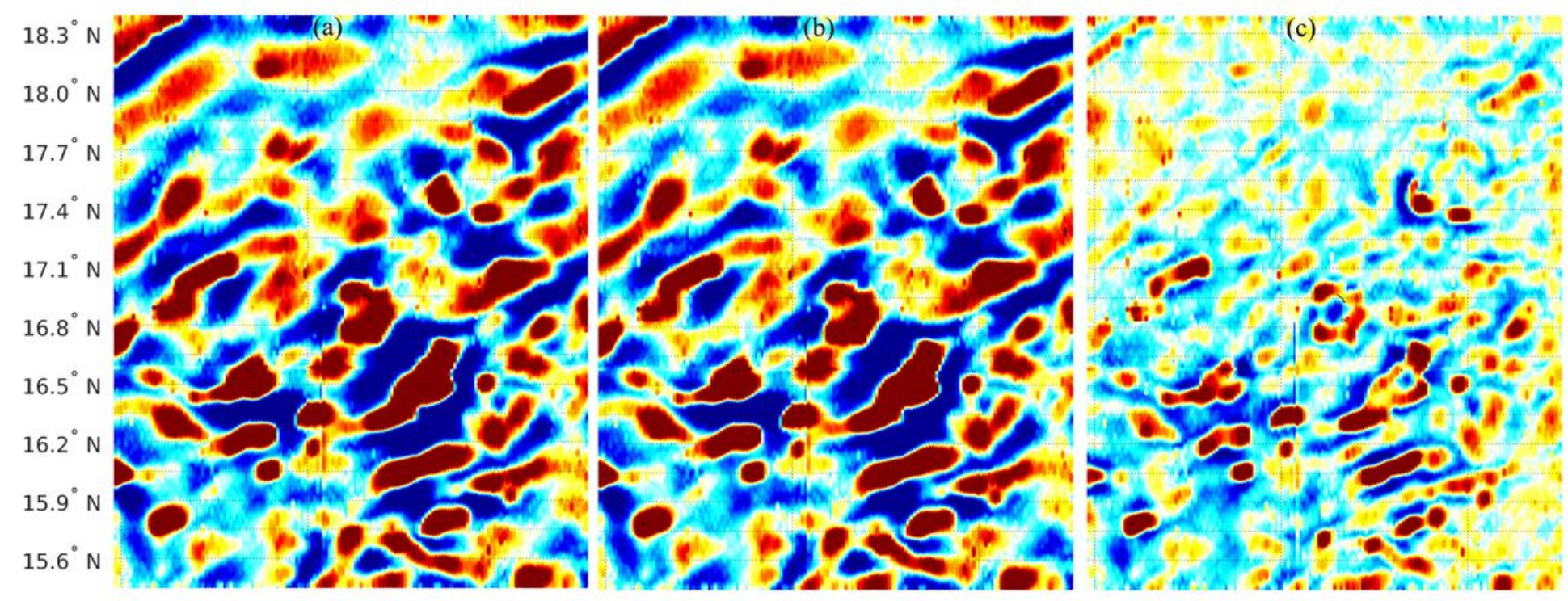

E $111.5^{\circ} \mathrm{E} 112.0^{\circ} \mathrm{E} 112.5^{\circ} \mathrm{E} 113.0^{\circ} \mathrm{E}$

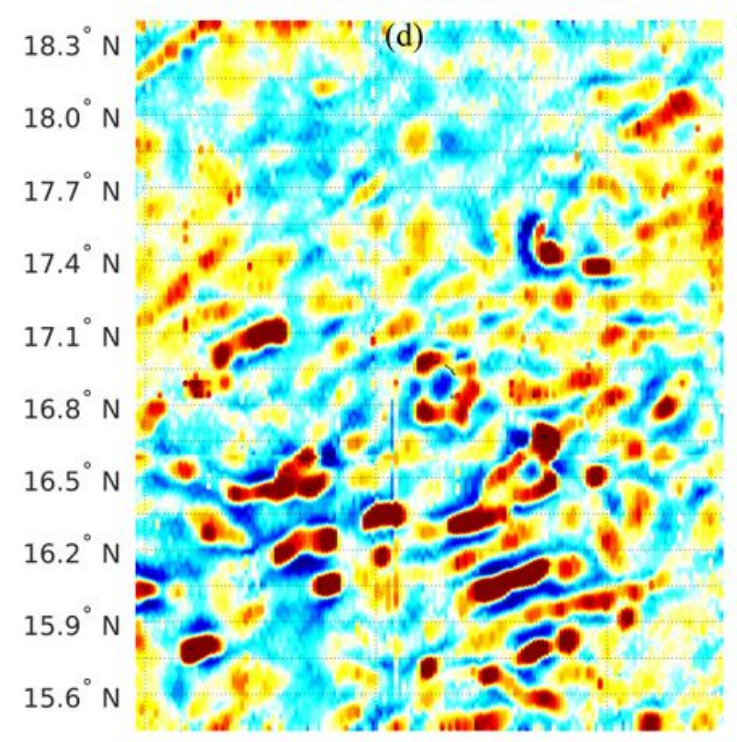

E $111.5^{\circ} \mathrm{E} 112.0^{\circ} \mathrm{E} 112.5^{\circ} \mathrm{E} 113.0^{\circ} \mathrm{E}$

$E 111.5^{\circ} \mathrm{E} 112.0^{\circ} \mathrm{E} 112.5^{\circ} \mathrm{E} 113.0^{\circ} \mathrm{E}$

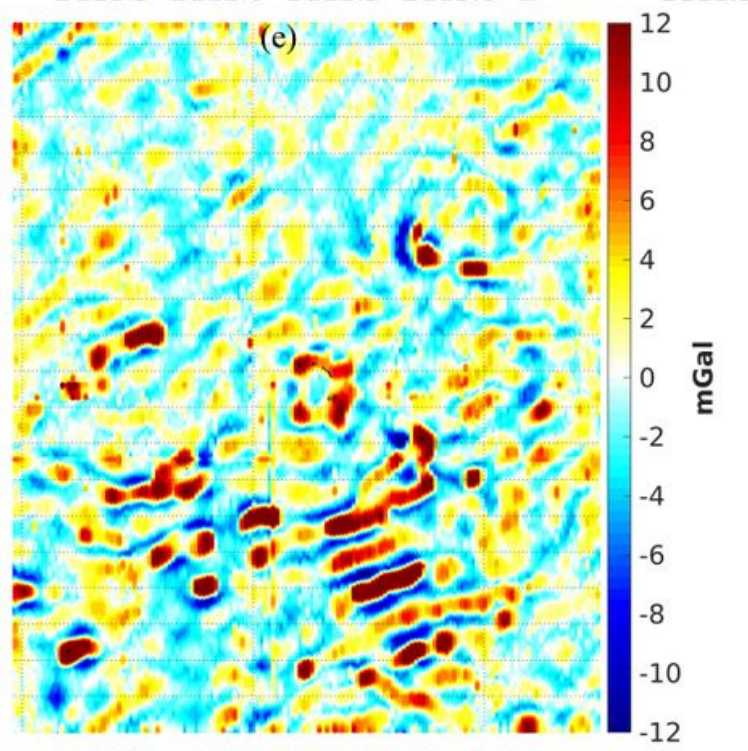

$111.0^{\circ} \mathrm{E} 111.5^{\circ} \mathrm{E} 112.0^{\circ} \mathrm{E} 112.5^{\circ} \mathrm{E} 113.0^{\circ} \mathrm{E}$

$1.0^{\circ} \mathrm{E} 111.5^{\circ} \mathrm{E} 112.0^{\circ} \mathrm{E} 112.5^{\circ} \mathrm{E} 113.0^{\circ} \mathrm{E}$

Figure 4

Difference between the airborne gravity measurements and data synthesized from (a) GOCO05c (d/o 720), (b) XGM2019 (d/o 760), (c) EGM2008 (d/o 2190), (d) EIGEN-6C4 (d/o 2190), and (e) XGM2019e_2159 (d/o 2190) over Paracel Islands. 

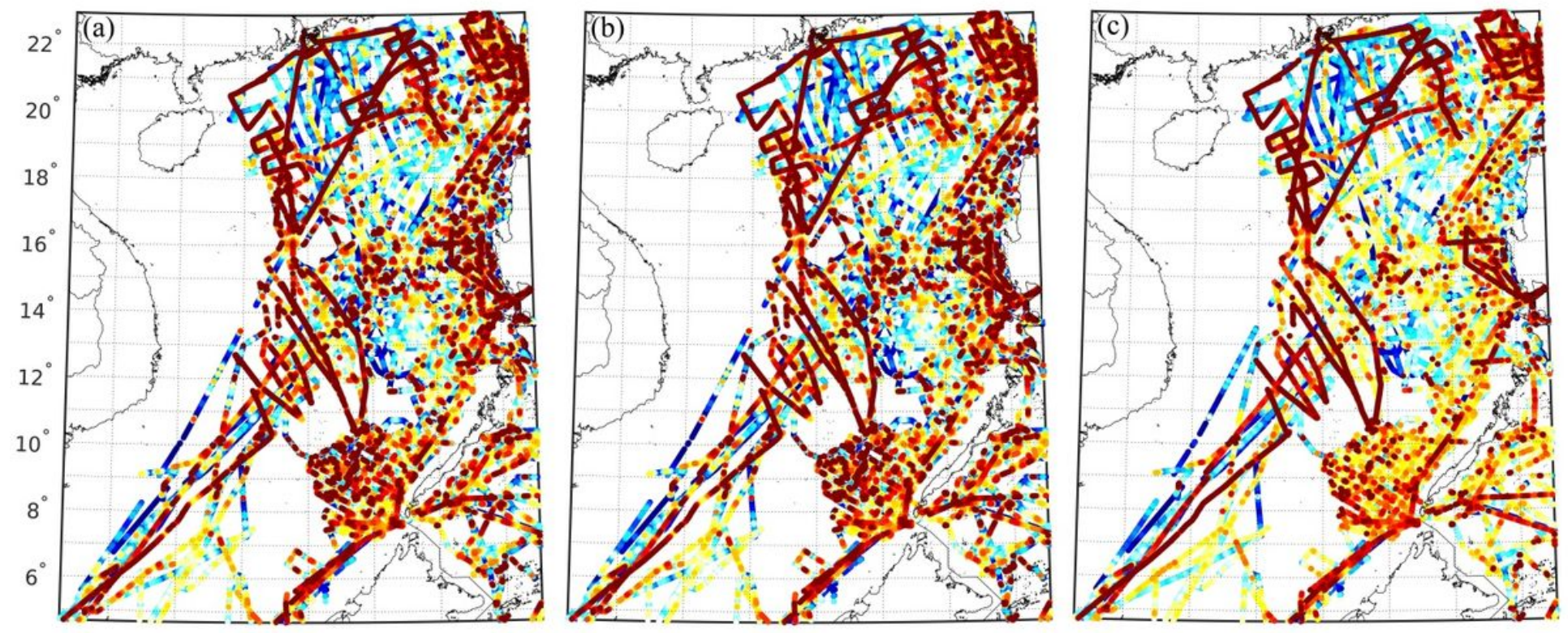

$108^{\circ} 110^{\circ} 112^{\circ} 114^{\circ} 116^{\circ} 118^{\circ} 120^{\circ}$

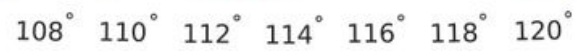

$108^{\circ} 110^{\circ} 112^{\circ} \quad 114^{\circ} 116^{\circ} 118^{\circ} 120^{\circ}$
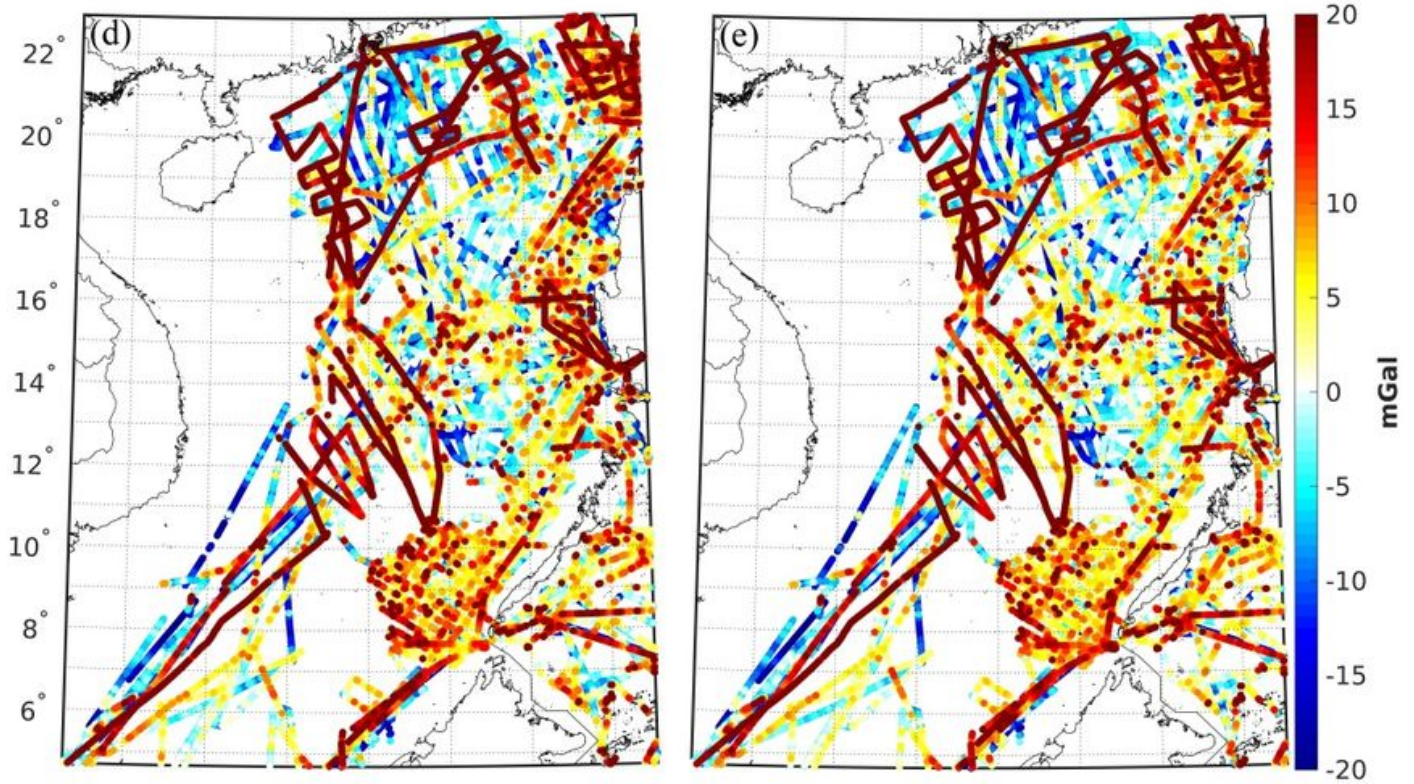

$108^{\circ} 110^{\circ} 112^{\circ} 114^{\circ} 116^{\circ} 118^{\circ} 120^{\circ}$

$108^{\circ} 110^{\circ} 112^{\circ} 114^{\circ} 116^{\circ} 118^{\circ} 120^{\circ}$

Figure 5

Difference between shipborne gravity data retrieved from NGDC and quantities synthesized from (a) GOCO05c (d/o 720), (b) XGM2019 (d/o 760), (c) EGM2008 (d/o 2190), (d) EIGEN-6C4 (d/o 2190), and (e) XGM2019e_2159 (d/o 2190) over South China Sea. Note: The designations employed and the presentation of the material on this map do not imply the expression of any opinion whatsoever on the part of Research Square concerning the legal status of any country, territory, city or area or of its authorities, or concerning the delimitation of its frontiers or boundaries. This map has been provided by the authors. 


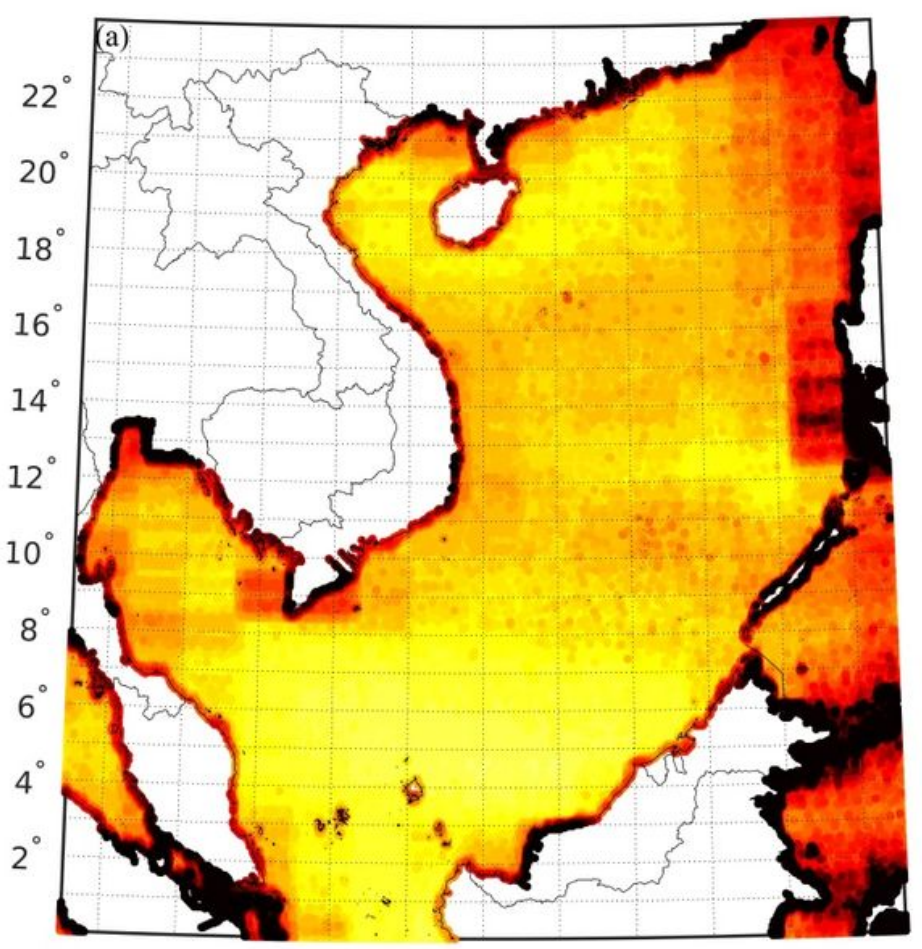

$100^{\circ} 102^{\circ} 104^{\circ} 106^{\circ} 108^{\circ} 110^{\circ} 112^{\circ} 114^{\circ} 116^{\circ} 118^{\circ} 120^{\circ}$

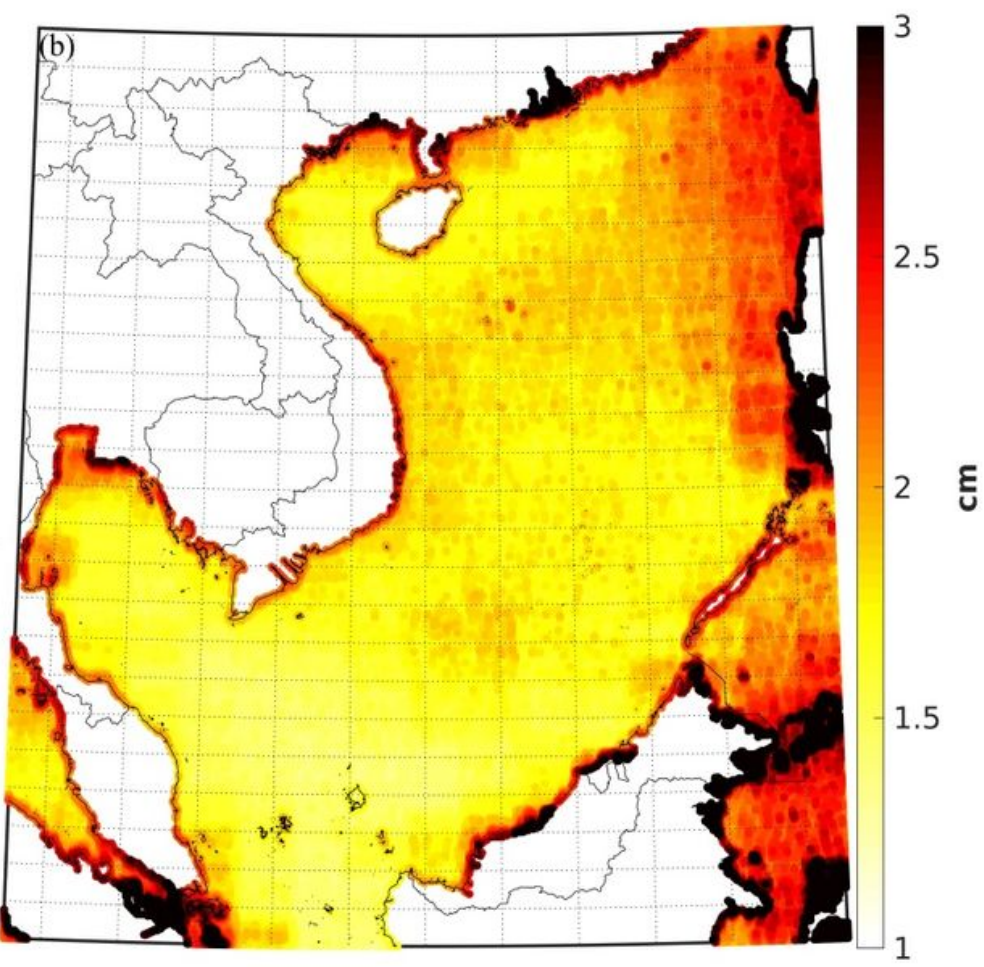

$100^{\circ} 102^{\circ} 104^{\circ} 106^{\circ} 108^{\circ} 110^{\circ} 112^{\circ} 114^{\circ} 116^{\circ} 118^{\circ} 120^{\circ}$

Figure 6

Interpolation errors of (a) DTU15MSS, and (b) DTU18MSS over South China Sea. Note: The designations employed and the presentation of the material on this map do not imply the expression of any opinion whatsoever on the part of Research Square concerning the legal status of any country, territory, city or area or of its authorities, or concerning the delimitation of its frontiers or boundaries. This map has been provided by the authors. 

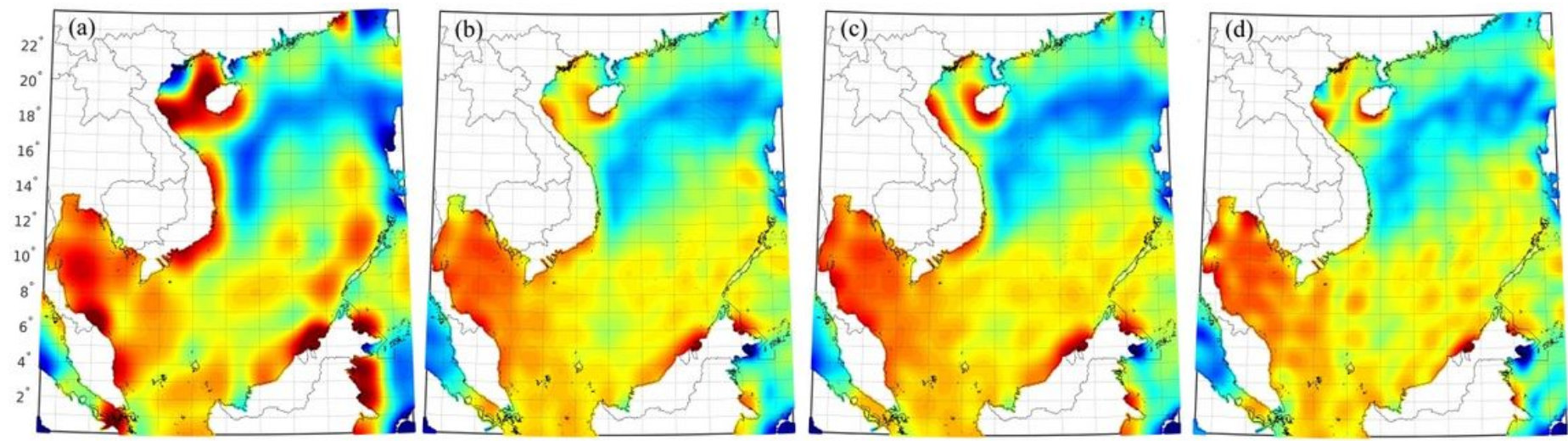

$100^{\prime} 102^{\circ} 104^{\circ} 106^{\circ} 108^{\circ} 110^{\circ} 112^{\circ} 114^{\circ} 116^{\circ} 118^{\circ} 120^{\circ} 100^{\circ} 102^{\circ} 104^{\circ} 106^{\circ} 108^{\circ} 110^{\circ} 112^{\circ} 114^{\circ} 116^{\circ} 118^{\circ} 120^{\circ} 100^{\circ} 102^{\circ} 104^{\circ} 106^{\circ} 108^{\circ} 110^{\circ} 112^{\circ} 114^{\circ} 116^{\circ} 118^{\circ} 120^{\circ} 100^{\circ} 102^{\circ} 104^{\circ} 106^{\circ} 108^{\circ} 110^{\circ} 112^{\circ} 114^{\circ} 116^{\circ} 118^{\circ} 120^{\circ}$
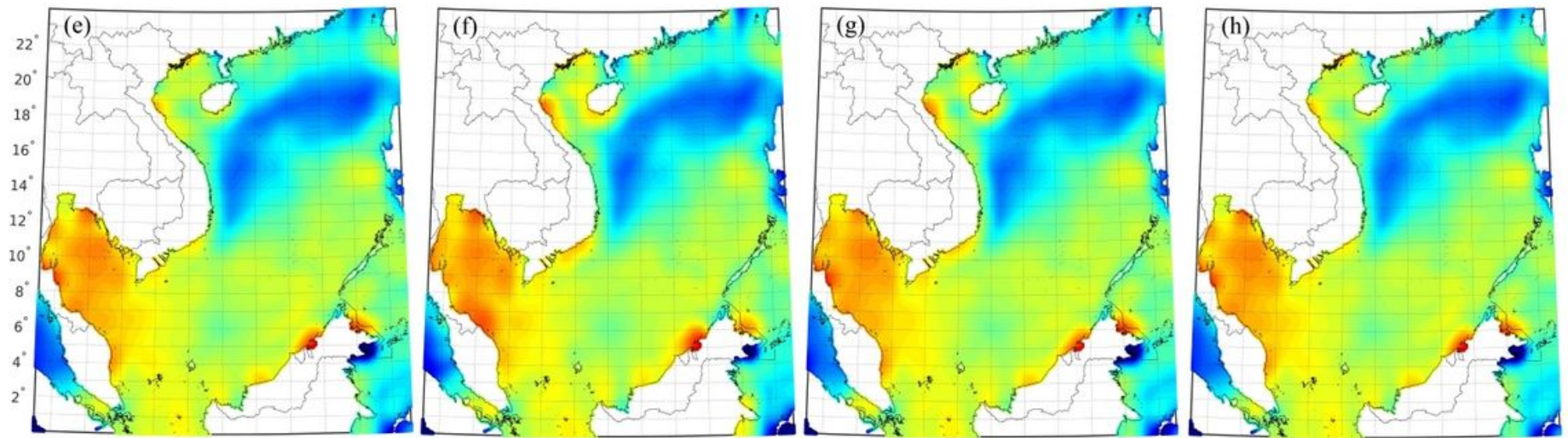

$100^{\circ} 102^{\circ} 104^{\circ} 106^{\circ} 108^{\circ} 110^{\circ} 112^{\circ} 114^{\circ} 116^{\circ} 118^{\circ} 120^{\circ} 100^{\circ} 102^{\circ} 104^{\circ} 106^{\circ} 108^{\circ} 110^{\circ} 112^{\circ} 114^{\circ} 116^{\circ} 118^{\circ} 120^{\circ} 100^{\circ} 102^{\circ} 104^{\circ} 106^{\prime \prime} 108^{\circ} 110^{\circ} 112^{\circ} 114^{\circ} 116^{\circ} 118^{\circ} 120^{\circ} 100^{\circ} 102^{\circ} 104^{\circ} 106^{\circ} 108^{\circ} 110^{\circ} 112^{\circ} 114^{\circ} 116^{\circ} 118^{\circ} 120^{\circ}$
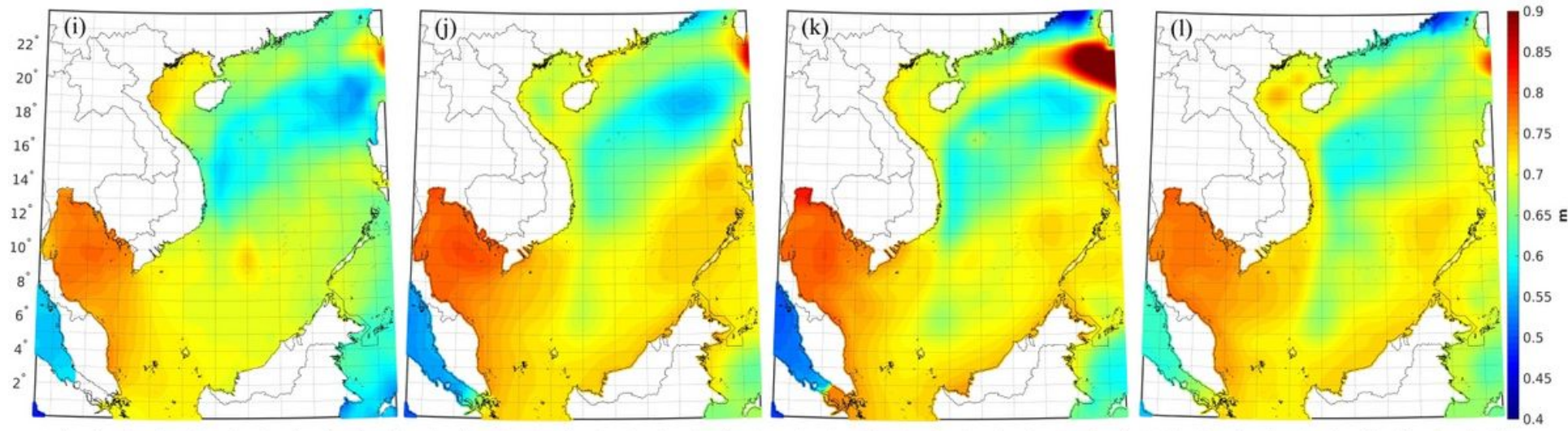

$100^{\circ} 102^{\circ} 104^{\circ} 106^{\circ} 108^{\circ} 110^{\circ} 112^{\circ} 114^{\circ} 116^{\circ} 118^{\circ} 120^{\circ} 100^{\circ} 102^{\circ} 104^{\circ} 106^{\circ} 108^{\circ} 110^{\circ} 112^{\circ} 114^{\circ} 116^{\circ} 118^{\circ} 120^{\circ} 100^{\circ} 102^{\circ} 104^{\circ} 106^{\circ} 108^{\circ} 110^{\circ} 112^{\circ} 114^{\circ} 116^{\circ} 118^{\circ} 120^{\circ} 100^{\circ} 102^{\circ} 104^{\circ} 106^{\circ} 108^{\circ} 110^{\circ} 112^{\circ} 114^{\circ} 116^{\circ} 118^{\circ} 120^{\circ}$

\section{Figure 7}

Geodetic MDT calculated from (a) EGM2008, (b) GECO, (c) SGG-UGM-1, (d) EIGEN-6C4, (e) XGM2019_2159, (f) GOCO05c, (g) XGM2016, and (h) XGM2019, and existing synthetic/ocean models, i.e., (i) CNES-CLS13MDT, (j) SODA, (k) ORAS5, and (I) OCCAM. Note: The designations employed and the presentation of the material on this map do not imply the expression of any opinion whatsoever on the part of Research Square concerning the legal status of any country, territory, city or area or of its authorities, or concerning the delimitation of its frontiers or boundaries. This map has been provided by the authors. 

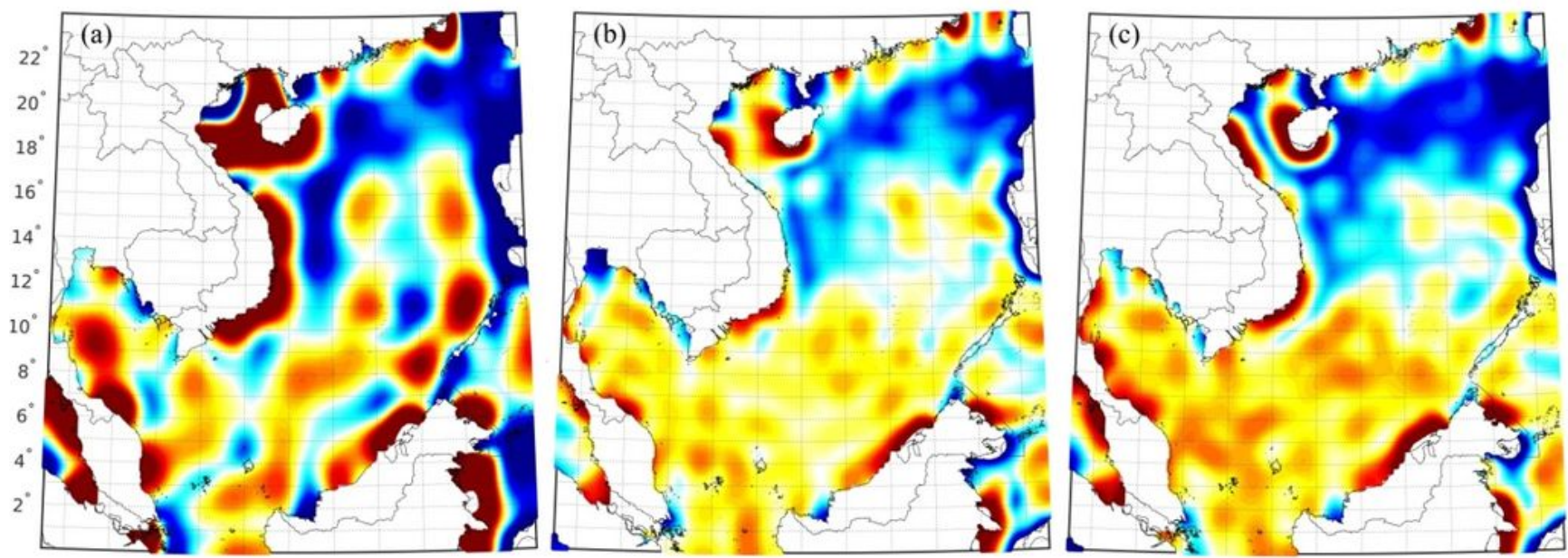

$100^{\circ} 102^{\circ} 104^{\circ} 106^{\circ} 108^{\circ} 110^{\circ} 112^{\circ} 114^{\circ} 116^{\circ} 118^{\circ} 120^{\circ}$

$100^{\circ} 102^{\circ} 104^{\circ} 106^{\circ} 108^{\circ} 110^{\circ} 112^{\circ} 114^{\circ} 116^{\circ} 118^{\circ} 120$

$100^{\circ} 102^{\circ} 104^{\circ} 106^{\circ} 108^{\circ} 110^{\circ} 112^{\circ} 114^{\circ} 116^{\circ} 118^{\circ} 120^{\circ}$
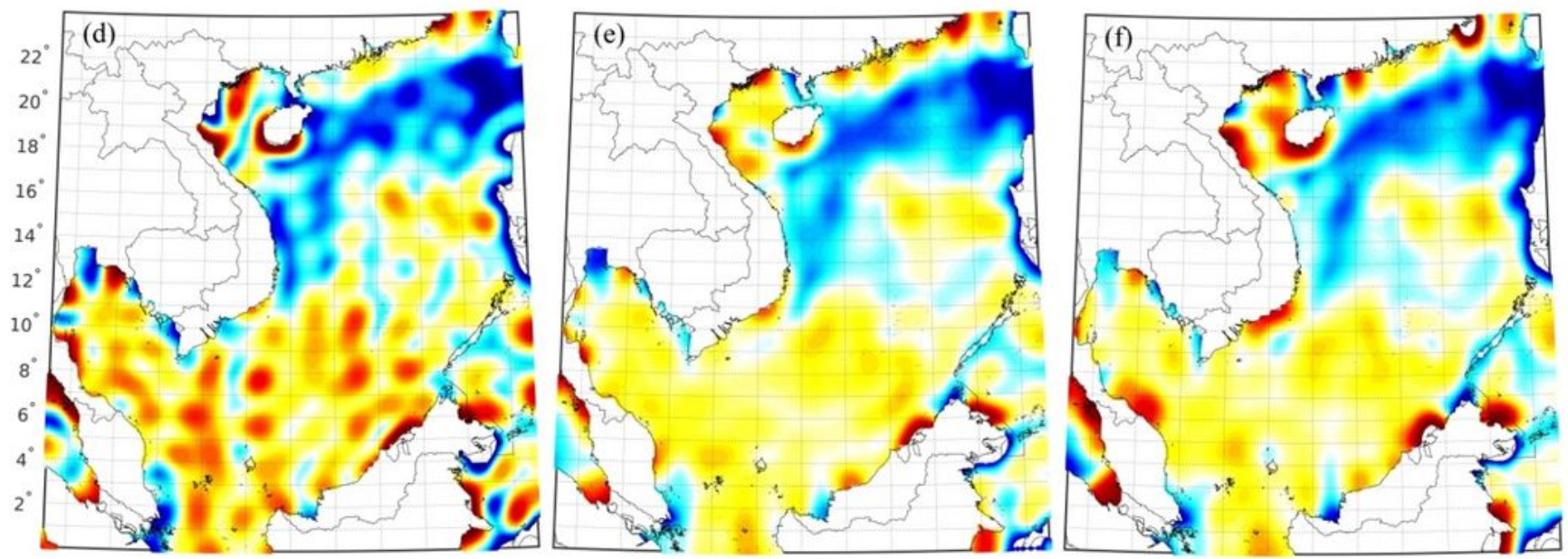

$100^{\circ} 102^{\circ} 104^{\circ} 106^{\circ} 108^{\circ} 110^{\circ} 112^{\circ} 114^{\circ} 116^{\circ} 118^{\circ} 120^{\circ}$

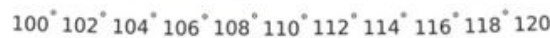

$100^{\circ} 102^{\circ} 104^{\circ} 106^{\circ} 108^{\circ} 110^{\circ} 112^{\circ} 114^{\circ} 116^{\circ} 118^{\circ} 120^{\circ}$
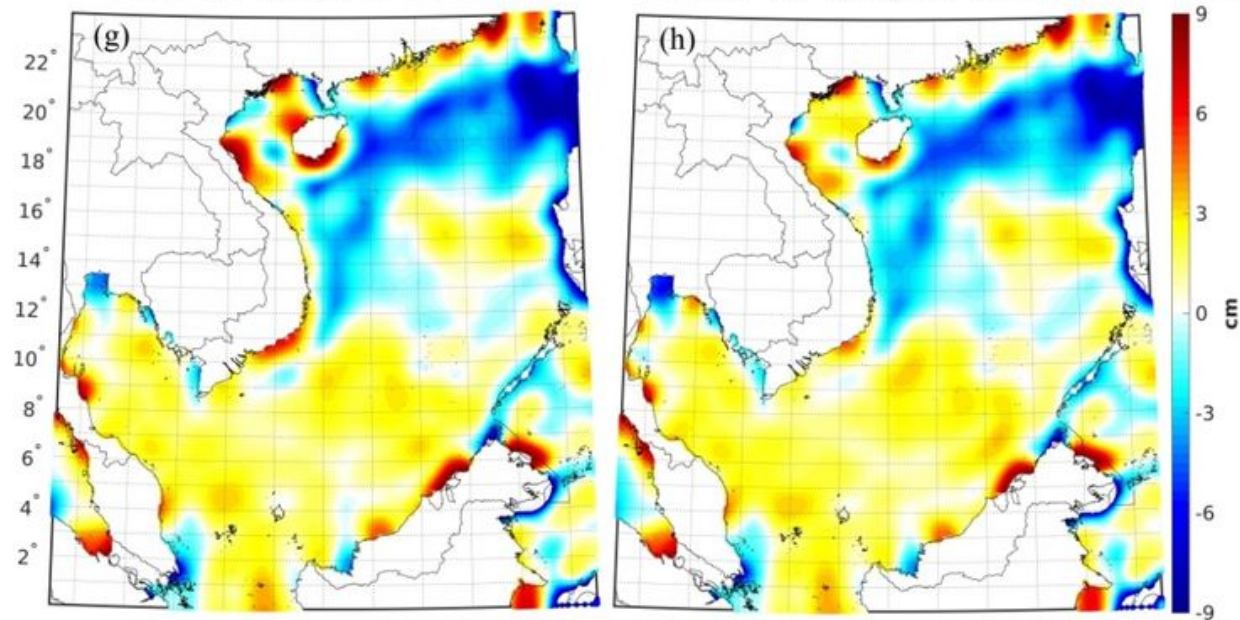

$100^{\circ} 102^{\circ} 104^{\circ} 106^{\circ} 108^{\circ} 110^{\circ} 112^{\circ} 114^{\circ} 116^{\circ} 118^{\circ} 120^{\circ} 100^{\circ} 102^{\circ} 104^{\circ} 106^{\circ} 108^{\circ} 110^{\circ} 112^{\circ} 114^{\circ} 116^{\circ} 118^{\circ} 120^{\circ}$

\section{Figure 8}

Difference between MDT computed from (a) EGM2008, (b) GECO, (c) SGG-UGM-1, (d) EIGEN-6C4, (e) XGM2019e_2159, (f) GOCO05c, (g) XGM2016, (h) XGM2019 and mean value of all synthetic/ocean models. Note: The designations employed and the presentation of the material on this map do not imply the expression of any opinion whatsoever on the part of Research Square concerning the legal status of 
any country, territory, city or area or of its authorities, or concerning the delimitation of its frontiers or boundaries. This map has been provided by the authors.
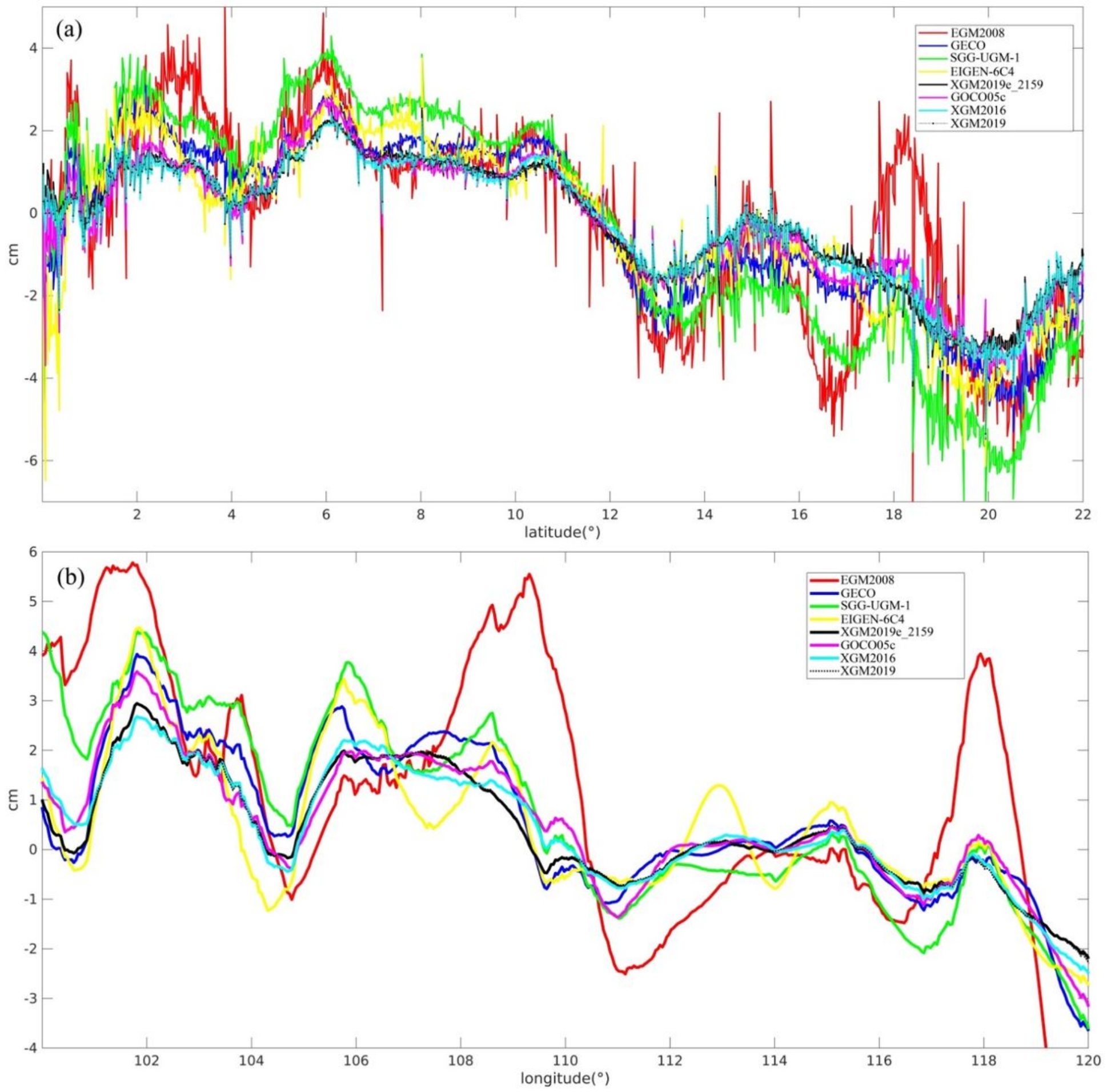

Figure 9

The zonal (a) and meridian (b) mean of the misfit between GGM-derived MDT and mean of all synthetic/ocean models. 

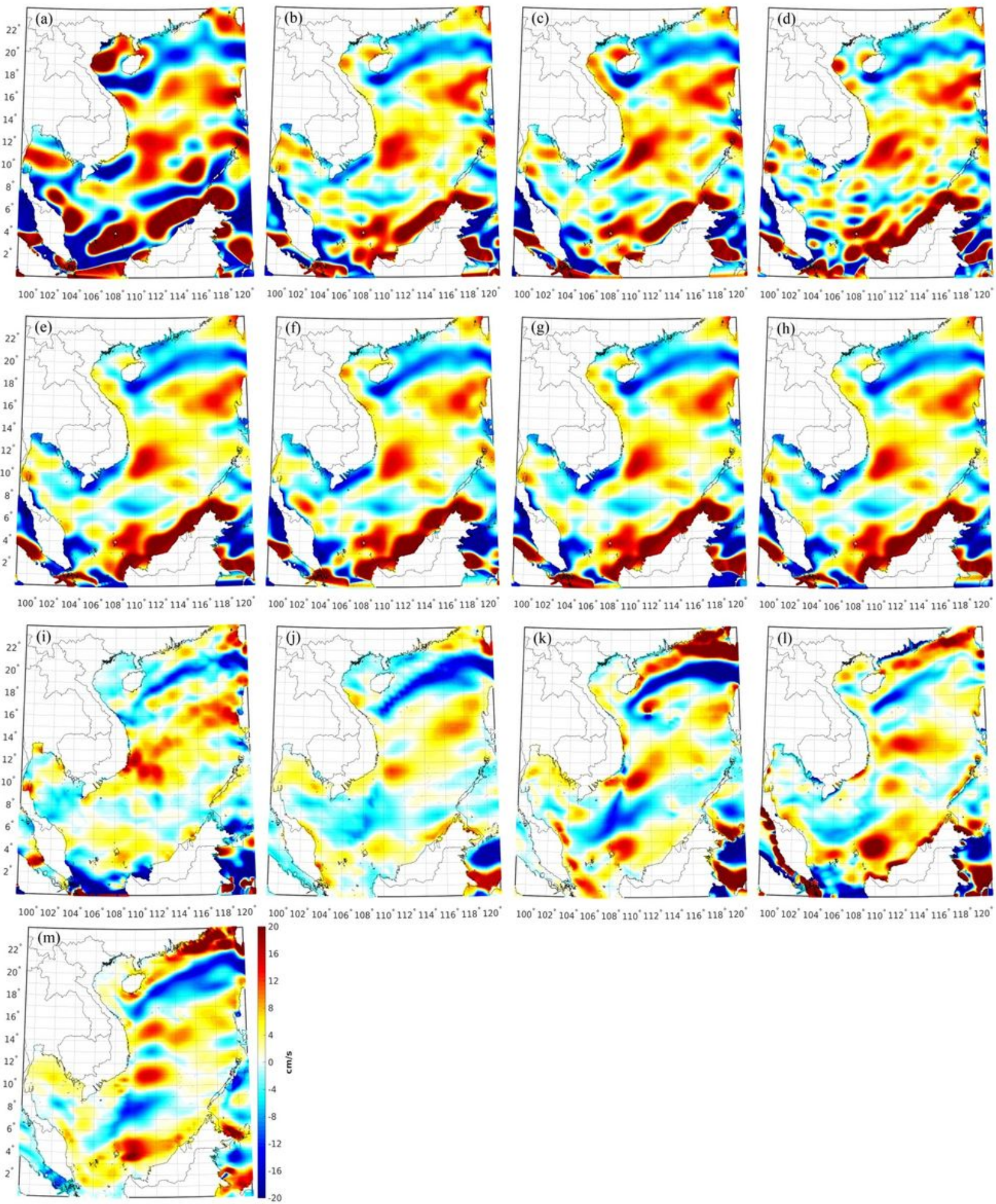

$100^{\circ} 102^{\circ} 104^{\circ} 106^{\circ} 108^{\circ} 110^{\circ} 112^{\circ} 114^{\circ} 116^{\circ} 118^{\circ} 120^{\circ}$

\section{Figure 10}

Zonal geostrophic velocities derived from (a) EGM2008, (b) GECO, (c) SGG-UGM-1, (d) EIGEN-6C4, (e) XGM2019_2159, (f) GOCO05c, (g) XGM2016, (h) XGM2019, (i) CNES-CLS13MDT, (j) SODA, (k) ORAS5, (l) OCCAM, and $(\mathrm{m})$ AIPO. Note: The designations employed and the presentation of the material on this map do not imply the expression of any opinion whatsoever on the part of Research Square concerning 
the legal status of any country, territory, city or area or of its authorities, or concerning the delimitation of its frontiers or boundaries. This map has been provided by the authors.
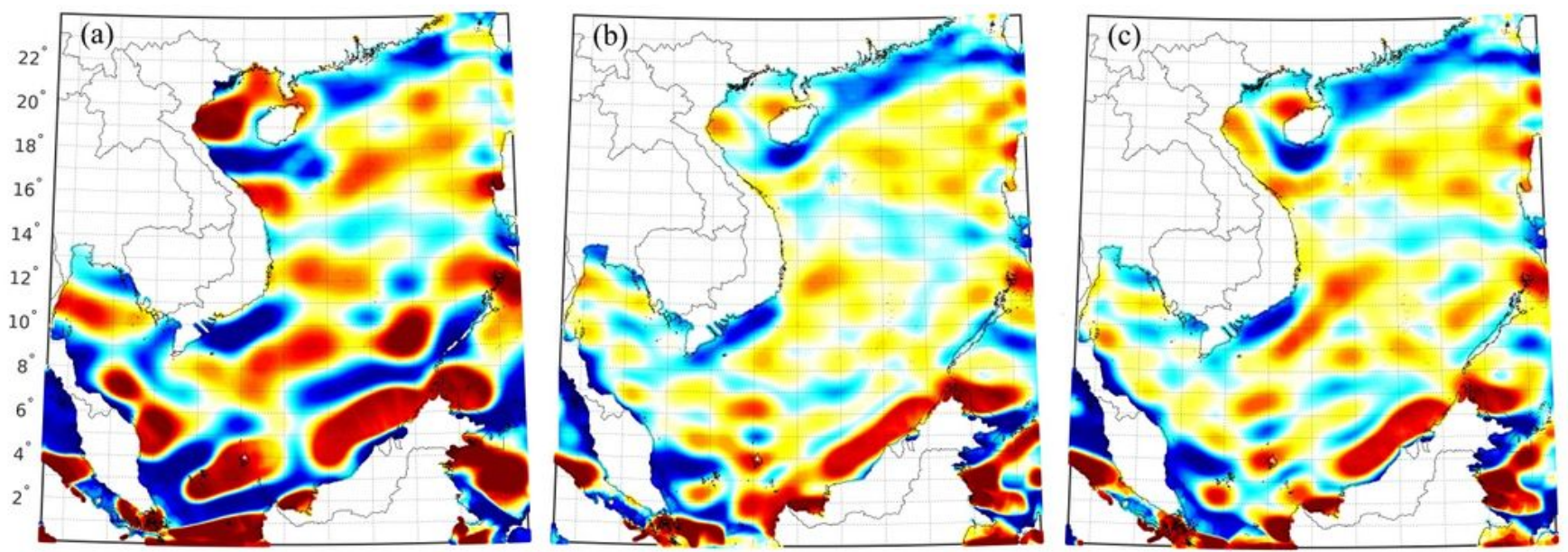

$100^{\circ} 102^{\circ} 104^{\circ} 106^{\circ} 108^{\circ} 110^{\circ} 112^{\circ} 114^{\circ} 116^{\circ} 118^{\circ} 120^{\circ}$

$100^{\circ} 102^{\circ} 104^{\circ} 106^{\circ} 108^{\circ} 110^{\circ} 112^{\circ} 114^{\circ} 116^{\circ} 118^{\circ} 120^{\circ}$

$100^{\circ} 102^{\circ} 104^{\circ} 106^{\circ} 108^{\circ} 110^{\circ} 112^{\circ} 114^{\circ} 116^{\circ} 118^{\circ} 120^{\circ}$
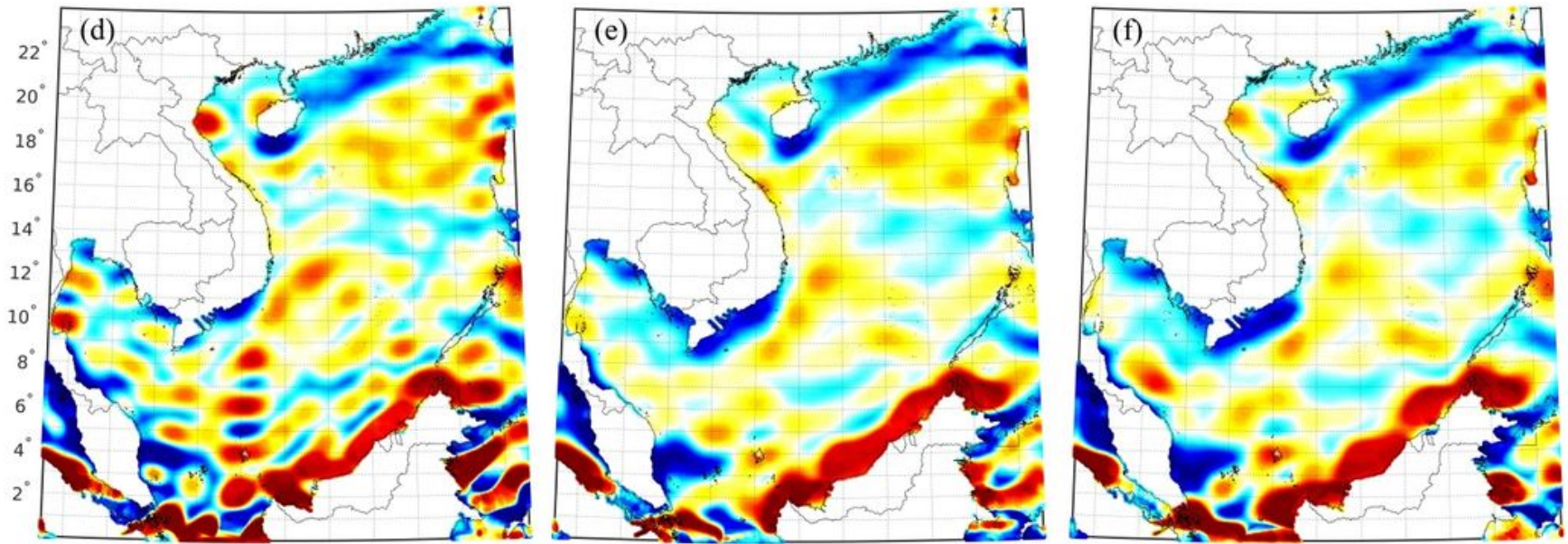

$100^{\circ} 102^{\circ} 104^{\circ} 106^{\circ} 108^{\circ} 110^{\circ} 112^{\circ} 114^{\circ} 116^{\circ} 118^{\circ} 120^{\circ}$

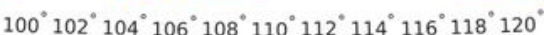

$100^{\circ} 102^{\circ} 104^{\circ} 106^{\circ} 108^{\circ} 110^{\circ} 112^{\circ} 114^{\circ} 116^{\circ} 118^{\circ} 120^{\circ}$
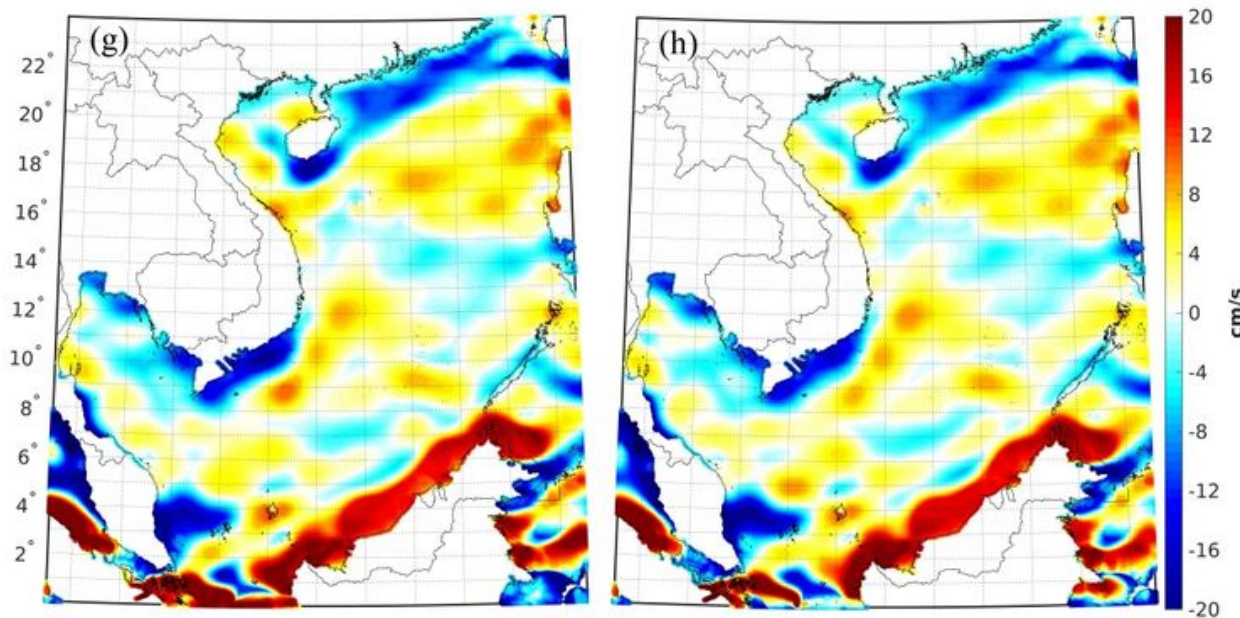

$100^{\circ} 102^{\circ} 104^{\circ} 106^{\circ} 108^{\circ} 110^{\circ} 112^{\circ} 114^{\circ} 116^{\circ} 118^{\circ} 120^{\circ}$

$100^{\circ} 102^{\circ} 104^{\circ} 106^{\circ} 108^{\circ} 110^{\circ} 112^{\circ} 114^{\circ} 116^{\circ} 118^{\circ} 120^{\circ}$

\section{Figure 11}

Difference between the zonal velocities computed from (a) MDT_EGM2008, (b) MDT_GECO, (c) MDT_SGG-UGM-1, (d) MDT_EIGEN-6C4, (e) MDT_XGM2019e_2159, (f) MDT_G0C005c, (g) MDT_XGM2016, (h) MDT_XGM2019 and the mean of all synthetic/ocean data.. Note: The designations 
employed and the presentation of the material on this map do not imply the expression of any opinion whatsoever on the part of Research Square concerning the legal status of any country, territory, city or area or of its authorities, or concerning the delimitation of its frontiers or boundaries. This map has been provided by the authors.
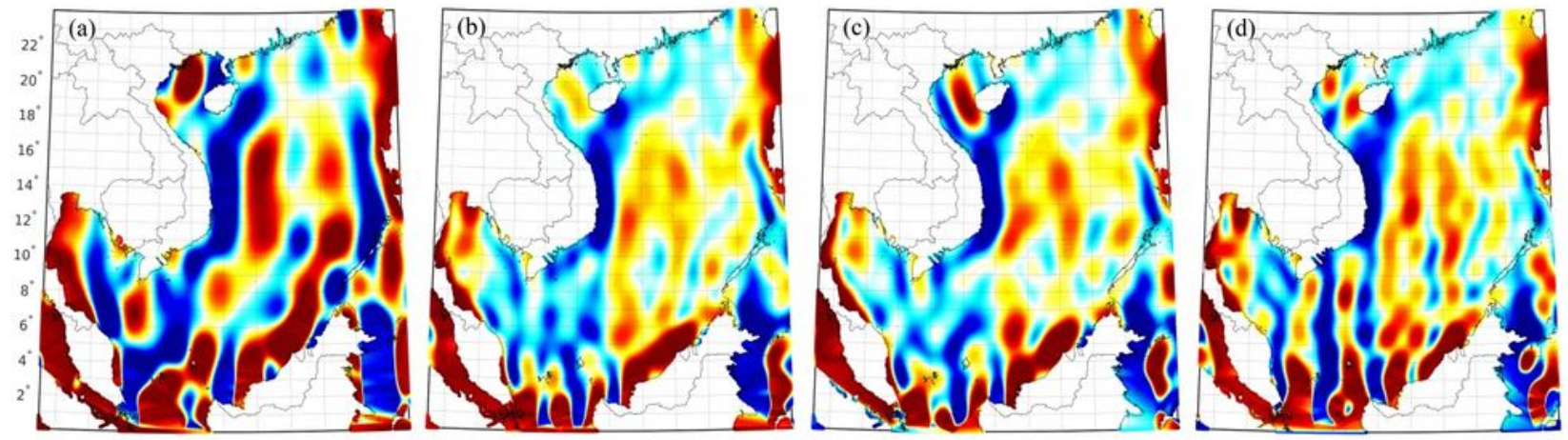

$100^{\circ} 102^{\circ} 104^{\circ} 106^{\circ} 108^{\circ} 110^{\circ} 112^{\circ} 114^{\circ} 116^{\circ} 118^{\circ} 120^{\circ}$

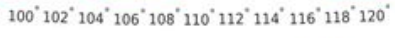

$100^{\circ} 102^{\circ} 104^{\circ} 106^{\circ} 108^{\circ} 110^{\circ} 112^{\circ} 114^{\circ} 116^{\circ} 118^{\circ} 120$
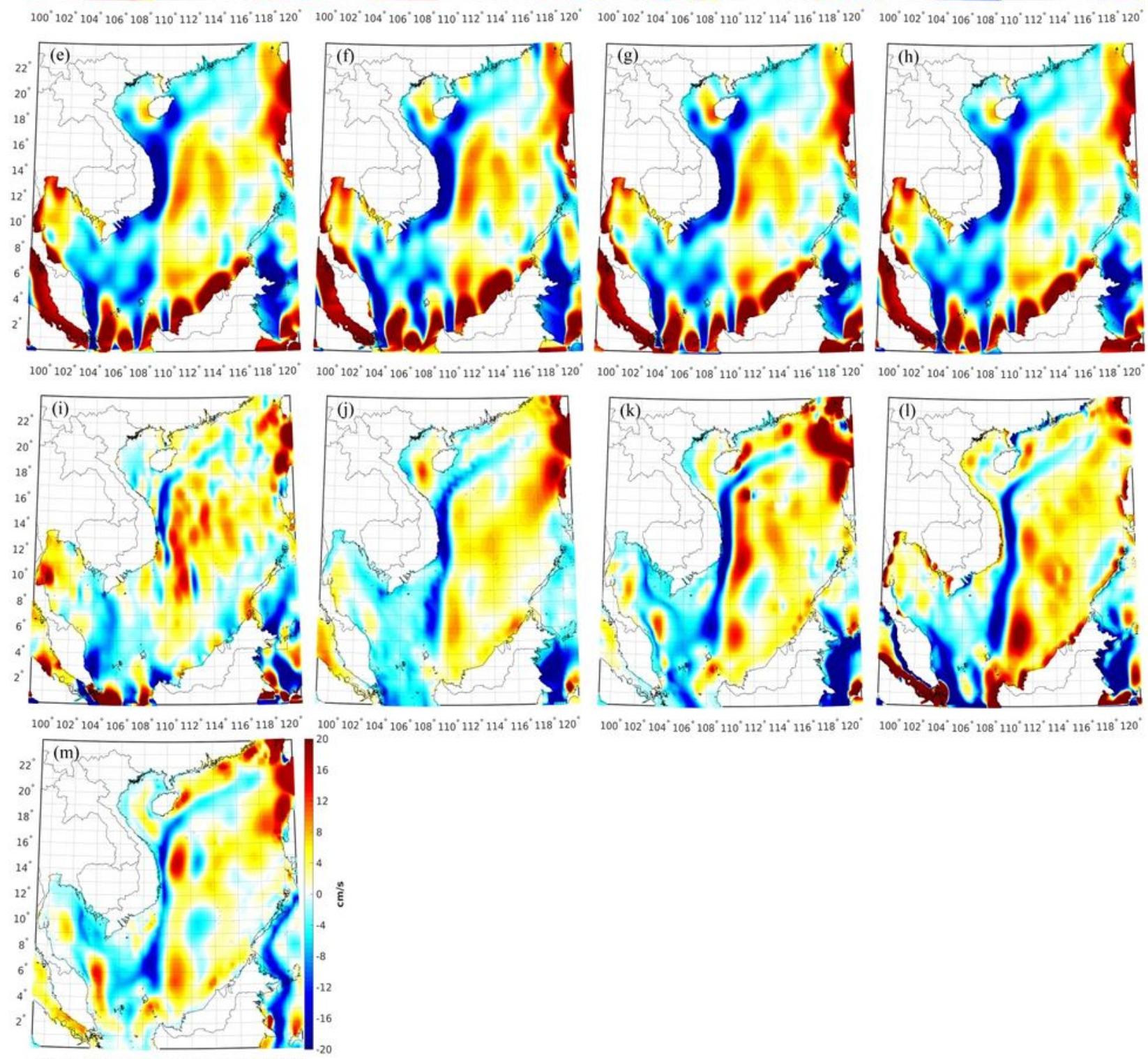

$100^{\circ} 102^{\circ} 104^{\circ} 106^{\circ} 108^{\circ} 110^{\circ} 112^{\circ} 114^{\circ} 116^{\circ} 118^{\circ} 120^{\circ}$

$100^{\circ} 102^{\circ} 104^{\circ} 106^{\circ} 108^{\circ} 110^{\circ} 112^{*} 114^{*} 116^{*} 118^{*} 120^{\prime}$

$100^{\circ} 102^{\prime} 104^{\circ} 106^{\circ} 108^{\circ} 110^{\circ} 112^{*} 114^{*} 116^{*} 118^{\circ} 120^{\circ}$

Figure 12 
Meridian geostrophic currents computed from (a) EGM2008, (b) GECO, (c) SGG-UGM-1, (d) EIGEN-6C4, (e) XGM2019_2159, (f) GOCO05c, (g) XGM2016, (h) XGM2019, (i) CNES-CLS13MDT, (j) SODA, (k) ORAS5, (l) OCCAM, and $(\mathrm{m})$ AIPO. Note: The designations employed and the presentation of the material on this map do not imply the expression of any opinion whatsoever on the part of Research Square concerning the legal status of any country, territory, city or area or of its authorities, or concerning the delimitation of its frontiers or boundaries. This map has been provided by the authors.

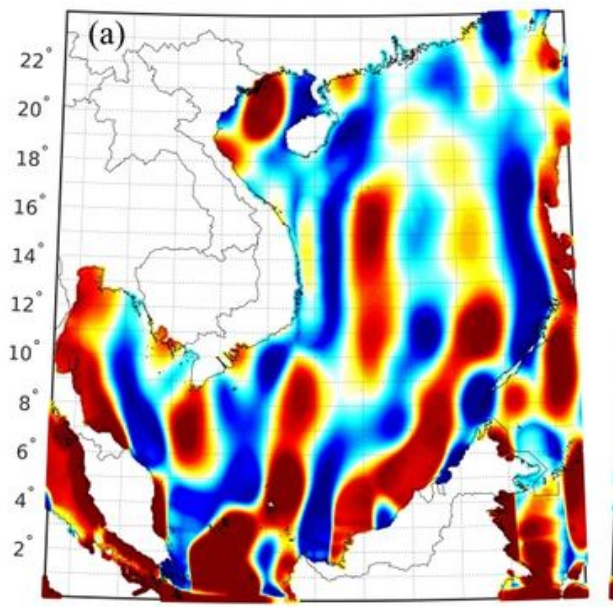

$100^{\circ} 102^{\circ} 104^{\circ} 106^{\circ} 108^{\circ} 110^{\circ} 112^{\circ} 114^{\circ} 116^{\circ} 118^{\circ} 120^{\circ}$

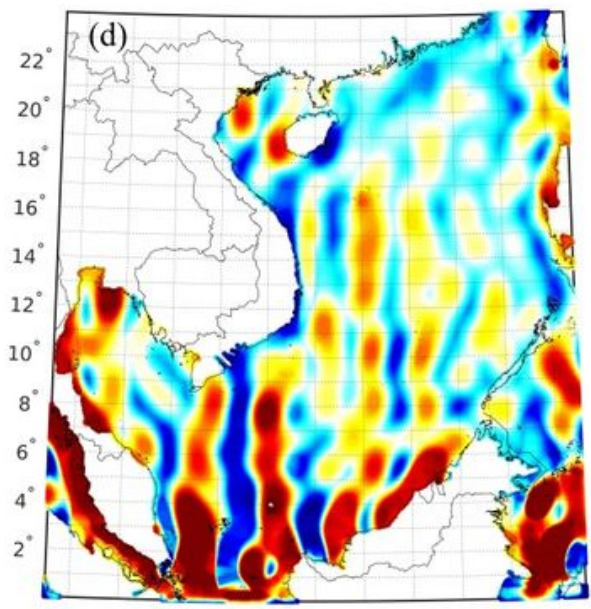

$100^{\circ} 102^{\circ} 104^{\circ} 106^{\circ} 108^{\circ} 110^{\circ} 112^{\circ} 114^{\circ} 116^{\circ} 118^{\circ} 120^{\circ}$

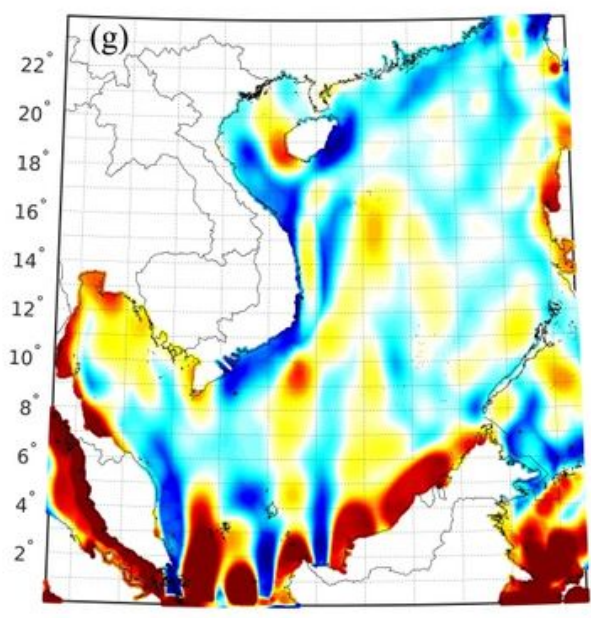

$100^{\circ} 102^{\circ} 104^{\circ} 106^{\circ} 108^{\circ} 110^{\circ} 112^{\circ} 114^{\circ} 116^{\circ} 118^{\circ} 120$

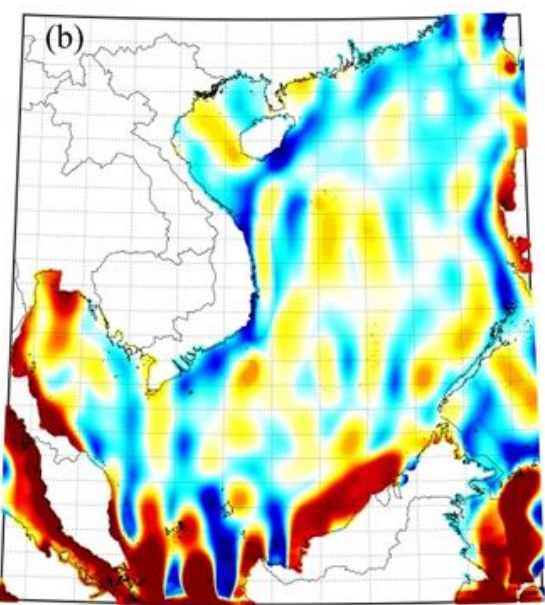

$100^{\circ} 102^{\circ} 104^{\circ} 106^{\circ} 108^{\circ} 110^{\circ} 112^{\circ} 114^{\circ} 116^{\circ} 118^{\circ} 120^{\circ}$

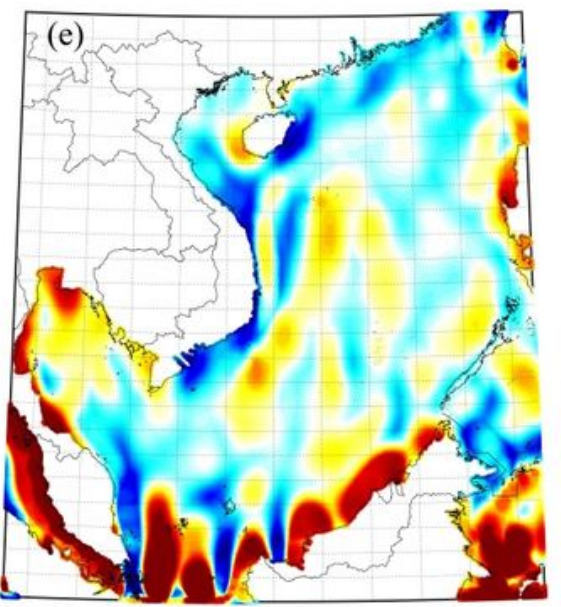

$100^{\circ} 102^{\circ} 104^{\circ} 106^{\circ} 108^{\circ} 110^{\circ} 112^{\circ} 114^{\circ} 116^{\circ} 118^{\circ} 120^{\circ}$

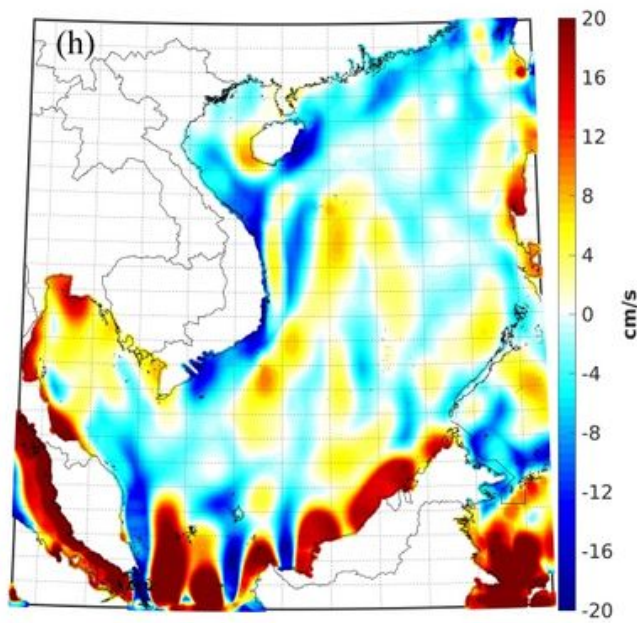

$100^{\circ} 102^{\circ} 104^{\circ} 106^{\circ} 108^{\circ} 110^{\circ} 112^{\circ} 114^{\circ} 116^{\circ} 118^{\circ} 120^{\circ}$

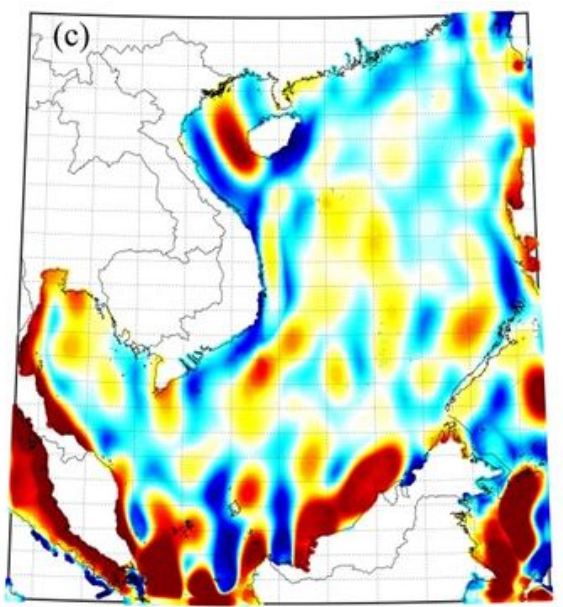

$100^{\circ} 102^{\circ} 104^{\circ} 106^{\circ} 108^{\circ} 110^{\circ} 112^{\circ} 114^{\circ} 116^{\circ} 118^{\circ} 120^{\circ}$

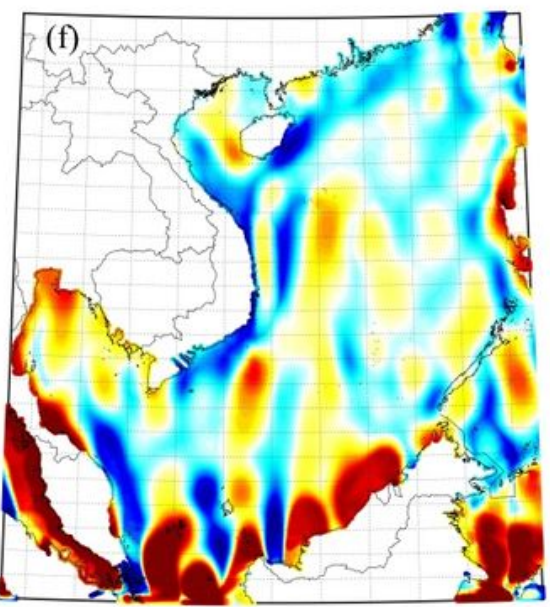

$100^{\circ} 102^{\circ} 104^{\circ} 106^{\circ} 108^{\circ} 110^{\circ} 112^{\circ} 114^{\circ} 116^{\circ} 118^{\circ} 120^{\circ}$ 
Difference between the meridian velocities computed from (a) MDT_EGM2008, (b) MDT_GECO, (c) MDT_SGG-UGM-1, (d) MDT_EIGEN-6C4, (e) MDT_XGM2019e_2159, (f) MDT_GOCO05c, (g) MDT_XGM2016, (h) MDT_XGM2019 and the mean of all synthetic/ocean models. Note: The designations employed and the presentation of the material on this map do not imply the expression of any opinion whatsoever on the part of Research Square concerning the legal status of any country, territory, city or area or of its authorities, or concerning the delimitation of its frontiers or boundaries. This map has been provided by the authors.

\section{Supplementary Files}

This is a list of supplementary files associated with this preprint. Click to download.

- floatimage14.jpeg

- GraphicalAbstract.png 